\title{
ENHANCED UPTAKE OF POLYETHYLENE GLYCOL COATED GOLD NANOPARTICLES FOR IMPROVED THERAPEUTICS
}

\author{
by \\ Charmainne Cruje \\ B. Sc., University of Toronto, 2010 \\ A thesis presented to Ryerson University \\ in partial fulfillment of the requirements for the degree \\ of Master of Science in Biomedical Physics
}

Toronto, Ontario, Canada, 2015

(C) Charmainne Cruje 2015 


\section{AUTHOR'S DECLARATION}

I hereby declare that I am the sole author of this thesis. This is a true copy of the thesis, including any required final revisions as accepted by my examiners.

I authorize Ryerson University to lend this thesis to other institutions or individuals for the purpose of scholarly research.

I further authorize Ryerson University to reproduce this thesis by photocopying or by other means, in total or in part, at the request of other institutions or individuals for the purpose of scholarly research.

I understand that my thesis may be made electronically available to the public.

\section{Charmainne Cruje}




\title{
ENHANCED UPTAKE OF POLYETHYLENE GLYCOL COATED GOLD NANOPARTICLES FOR IMPROVED THERAPEUTICS
}

\author{
Charmainne Cruje \\ Master of Science \\ Biomedical Physics, 2015 \\ Ryerson University
}

\begin{abstract}
Polyethylene glycol (PEG) has promoted the prospective cancer treatment applications of gold nanoparticles (GNPs). PEG is widely used in providing GNPs with stealth properties, hence prolonging blood circulation times. GNPs coated with PEG (PEG-GNPs) take advantage of the enhanced permeability and retention effect in tumor environments, making them suitable for targeted treatment. The cellular uptake of PEG-GNPs is significantly lower than uncoated GNPs in vitro. PEG minimizes PEG-GNP interaction with ligands that mediate cancer cell uptake, causing reduced GNP uptake in comparison to uncoated GNP. As intracellular localization of GNPs maximizes its therapeutic enhancement, there is a need to improve the uptake of PEG-GNPs. To improve cell entry, receptor mediated endocytosis peptides were conjugated with PEG-GNPs of varying core sizes. Spherical GNPs of diameters 14,50 and $70 \mathrm{~nm}$ with a PEG chain length of $2 \mathrm{kDa}$ were used to determine a preferred core size for uptake in vitro in HeLa and MDAMB-231 cells. A preliminary study using surface-modified GNPs as a radiosensitizer to a megavoltage clinical photon beam was done to assess its therapeutic application.
\end{abstract}


To my family. 


\section{TABLE OF CONTENTS}

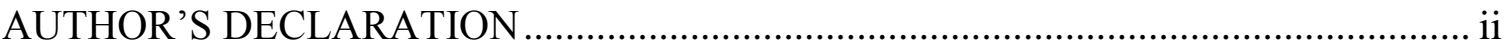

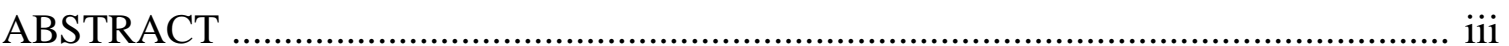

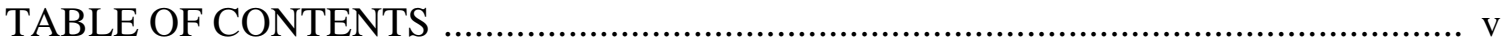

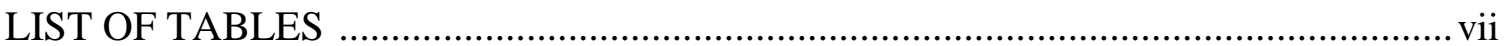

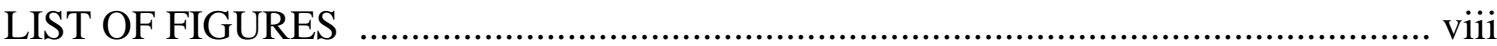

ACKNOWLEDGEMENTS ………………………….................................... ix

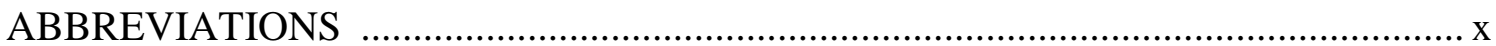

Chapters

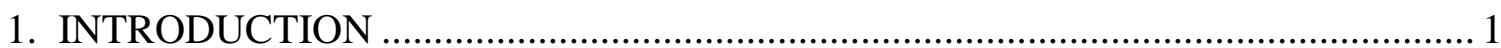

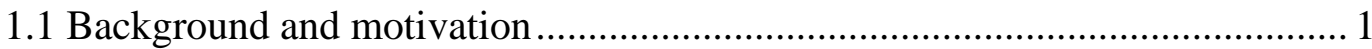

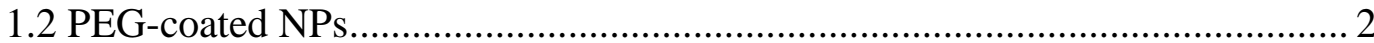

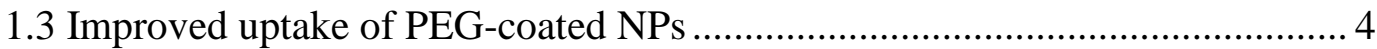

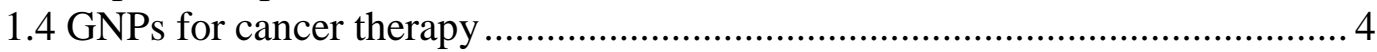

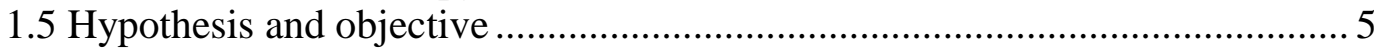

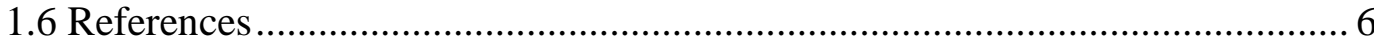

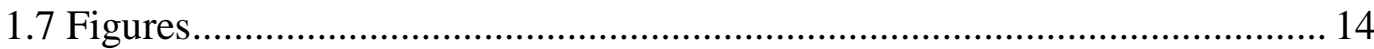

2. INTEGRATION OF PEPTIDES FOR ENHANCED UPTAKE OF PEGYLATED

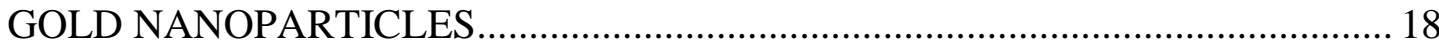

2.1 Preface

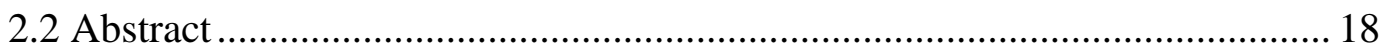

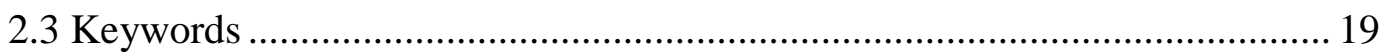

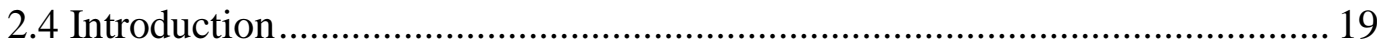

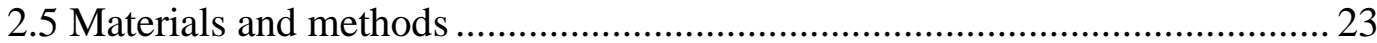

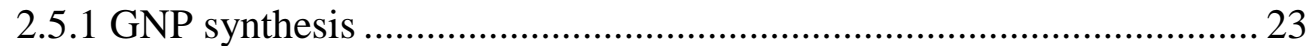

2.5.2 Characterization and PEGylation of GNPs ....................................... 24

2.5.3 Peptide-functionalization of PEG-GNP ............................................ 24

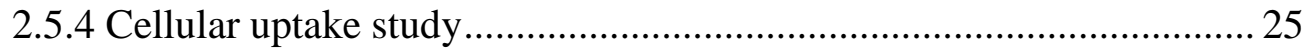




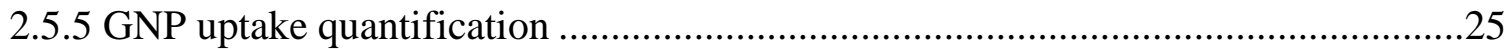

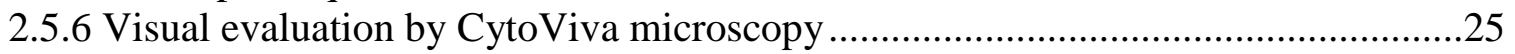

2.6 Results and discussion ........................................................................ 26

2.6.1 Characterization of citrate-capped (as-made) GNPs ..........................................26

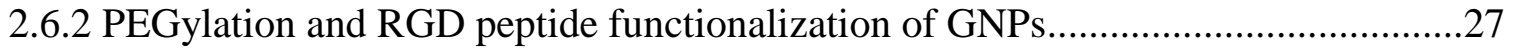

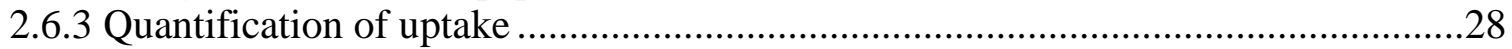

2.6.4 CytoViva imaging of extracellular and intracellular NPs ...................................29

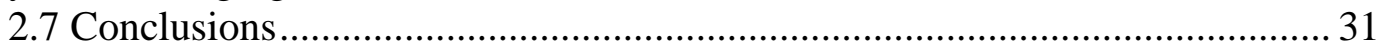

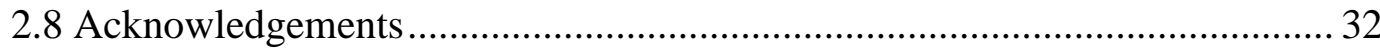

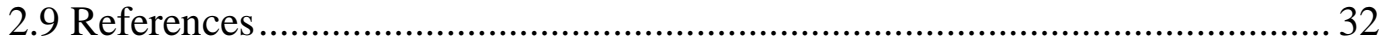

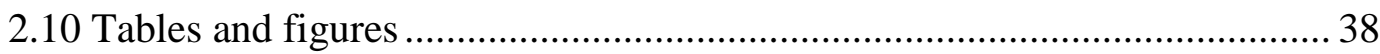

2.11 Contribution of authors to manuscript ................................................. 44

2.12 Permission for copyrighted material ....................................................... 44

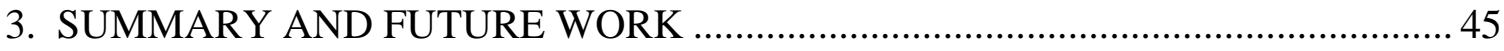

3.1 Uptake dependence on varying peptide to PEG ratios............................... 45

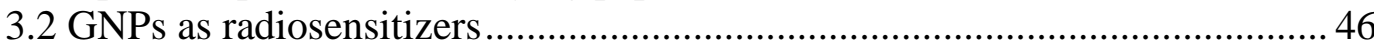

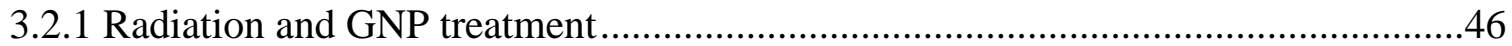

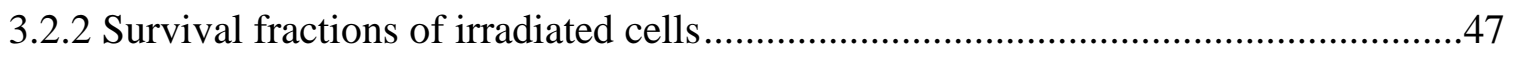

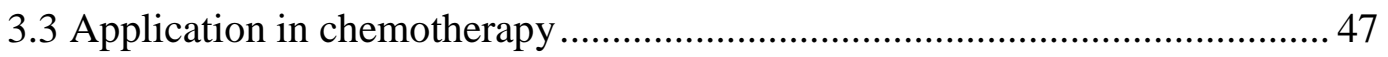

3.4 Enhanced uptake using other membrane receptors................................... 48

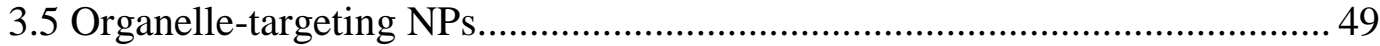

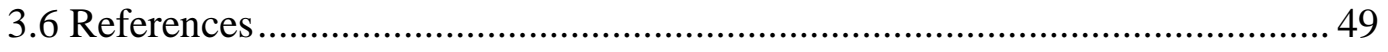

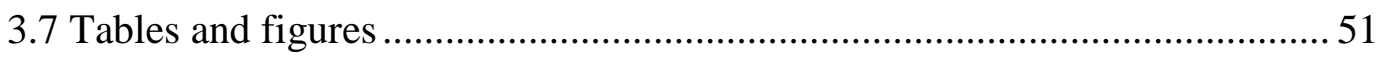




\section{LIST OF TABLES}

2.1 GNP mean diameter via UV-visible spectra and DLS............................................... 38

3.1 Survival fraction of irradiated and GNP treated HeLa cells ......................................... 51

3.2 Cell lines and proposed targeting cell membrane receptor ....................................... 52 


\section{LIST OF FIGURES}

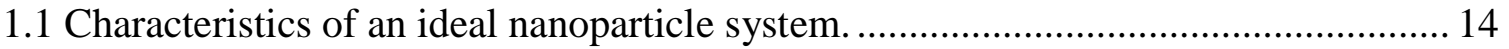

1.2 PEG conformation on NP surface depends on grafting density ............................. 15

1.3 The RME process of GNP entry into cells........................................................ 16

1.4 Hypothesis on improved therapeutic effect due to GNPs and enhanced cancer cell

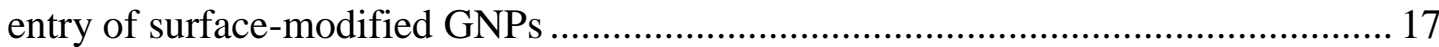

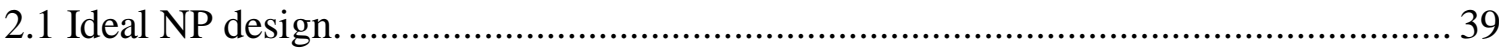

2.2 Size, surface and cell line dependence of NP cellular uptake................................ 40

2.3 Uptake of RGD-PEG functionalized NPs and its dependence on core size. ............. 41

2.4 Hyperspectral imaging of monodisperse and aggregated GNPs.............................. 42

2.5 CytoViva darkfield images of $14 \mathrm{~nm}$ NPs in cancer cells and

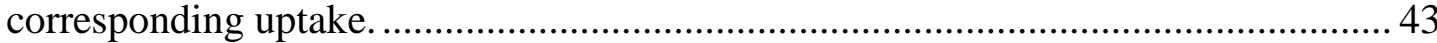

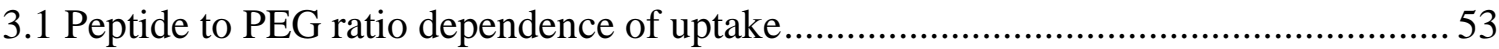

3.2 Irradiation experiment setup using $6 \mathrm{MeV}$ photons.............................................. 54

3.3 Survival fraction of HeLa cells treated with $2 \mathrm{~Gy}$ of $6 \mathrm{MeV}$ photons....................... 55

3.4 Proposed drug experiment using surface-modified GNPs as

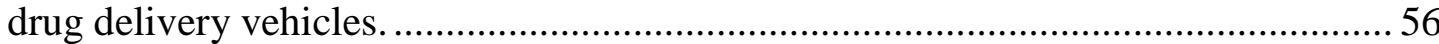

3.5 Proposed experiment with organelle-targeting RGD-PEG-GNPs. .......................... 57 


\section{ACKNOWLEDGEMENTS}

I would like to thank Dr. Devika Chithrani, who spends a lot of time in guiding me through my Master's study. She gave me many opportunities to present my work through attending conferences and publications. She has pushed me further than anyone ever has, which has helped me mature academically and personally.

I would also like to thank my committee members, Dr. Yuan Xu and Dr. Michael C. Kolios, who always find time to provide feedback regardless of their busy schedules. They guided me in completing my studies by helping me make wise research decisions and prudent academic choices. I am privileged to have such committee members.

I am pleased to thank the Chithrani group members: Celina Yang and Darren Yohan. Celina spends a lot of time on general lab management and put numerous lab protocols together. Darren dealt with all CytoViva microscope-related problems. I am fortunate to be in a group with excellent teamwork and collaboration skills. I would also like to thank Dr. Monique van Prooijen for helping us with the irradiation experiments.

Most important of all, I would like to thank my family for their endless love and support. 


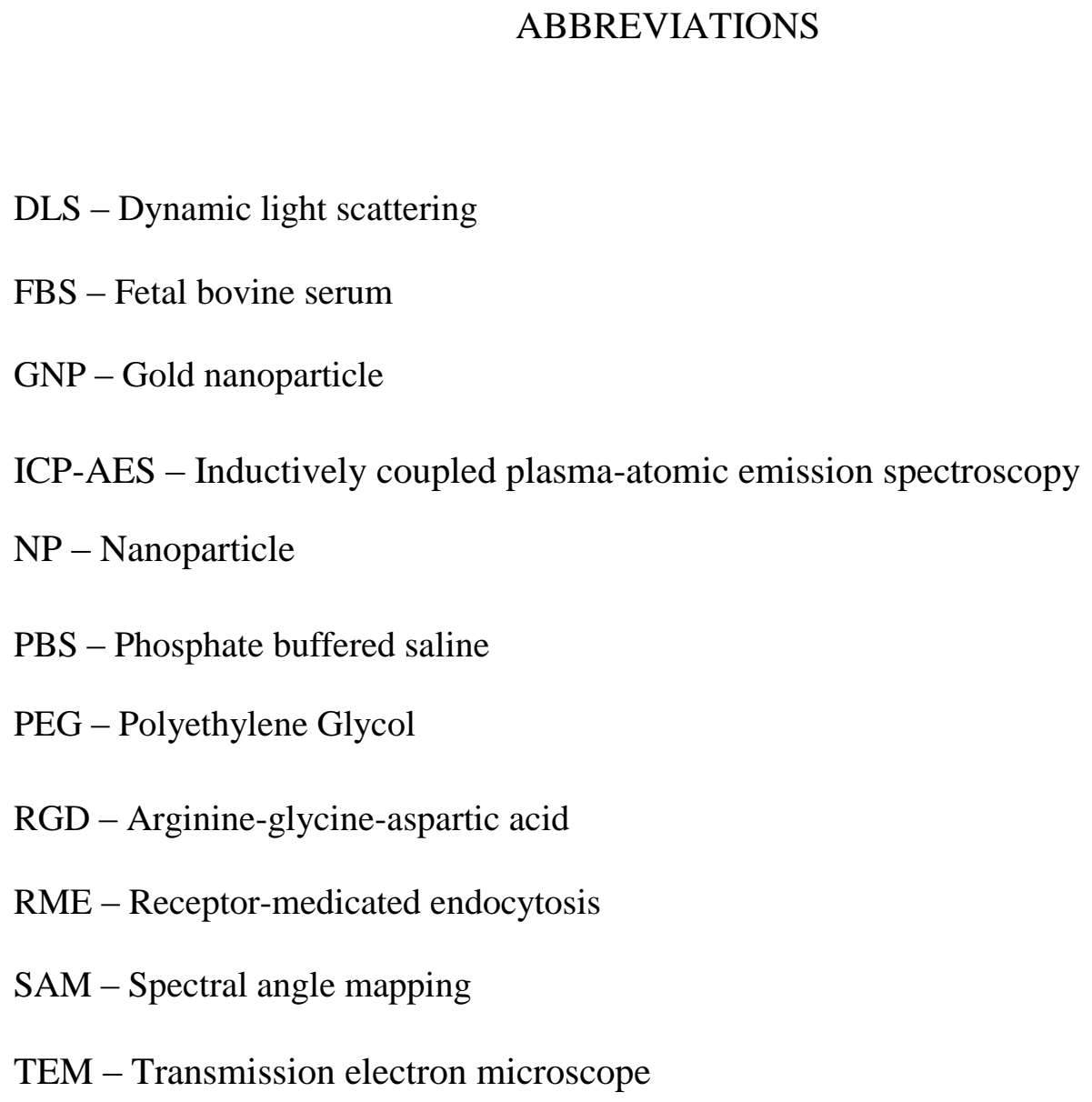




\section{CHAPTER 1}

\section{INTRODUCTION}

\section{$\underline{1.1 \text { Background and motivation }}$}

The biomedical research of inorganic nanoparticles (NPs) has developed NPbased cancer therapeutics and imaging. ${ }^{1-5}$ Through such applications, disease may be managed safely and more efficiently. ${ }^{2,4,6,7}$ Though not yet clinical, NP platforms are being developed to target therapeutics to tumors while minimizing interaction with normal tissue. ${ }^{8}$ To achieve an efficient NP system, prolonged in vivo residency time, preferential localization in tumor environments and cancer cell internalization for applications that favor intracellular localization is required (Figure 1.1). ${ }^{9,10}$ The first requirement of longer blood circulation time is most important because NPs should not be cleared from the body before its interaction with tumor tissue. To achieve favorable blood circulation times and cancer cell targeting, various NP sizes, shapes and surfaces have been studied. ${ }^{11,12,13}$ For example, gold NPs (GNPs) whose surface was modified with folic acid was found to target cancer cells versus healthy cells as it was found to deliver doxorubicin more effectively to HeLa cells in comparison to MDCK cells. ${ }^{14}$ Similarly, magnetic iron oxide NPs that targeted urokinase plasminogen activator receptors were found effective for drug delivery and imaging of cells that overexpressed such receptors. ${ }^{15}$ However, prior to cancer cell targeting, long blood circulation times must be achieved so that NPs may enter tumor tissue to 
begin with. This is achieved by surface modification of NPs with polyethylene glycol (PEG) or PEGylation, as found in numerous in vivo studies. $7,9,10,12,13,16-20$

\section{$\underline{1.2 \text { PEG-coated NPs }}$}

PEG is widely used in providing NPs with stealth properties, hence prolonging blood circulation times. ${ }^{18,19}$ For example, Lipka et al. showed that a longer PEG chain length of $10 \mathrm{kDa}$ improved NP blood circulation time as over $15 \%$ of applied volume was found after 24 hours in the bloodstream of mice subjects. ${ }^{27}$ On the other hand, its unmodified counterpart was cleared within an hour of intravenous application. Likewise, Cho et al. found that PEG-coated NPs accumulate in immune system organs responsible for NP body clearance for more than six months. ${ }^{18}$ The molecule accomplishes this by surrounding NPs with a hydrophilic layer, protecting the NP surface from the environment. $9,12,17,19,21,22$

High density grafting of polymers allow such molecules to assume what is referred to as a brush conformation as opposed to a mushroom configuration at low density (Figure 1.2). ${ }^{23}$ In addition to grafting density, conformations are determined by polymer chain length $(n)$, monomer length $(\alpha)$, and solvent type $(v)$ as shown in equation (1). ${ }^{23,24}$

$$
R=\alpha n^{v}
$$


Here, $R$ is the Flory radius, which defines the minimum distance required between grafted molecules to achieve a mushroom conformation, while $2 R$ is the maximum distance for sufficient surface coverage by the polymer. ${ }^{25}$ Molecules spaced less than $R$ have lower conformational freedom such that a brush conformation is achieved. For example, PEG, whose monomer length is $0.35 \mathrm{~nm}$, with a molecular weight of $2 \mathrm{kDa}$ (polymer chain length of 45.45$)$ in water $(v=3 / 5), R$ is $3.5 \mathrm{~nm}$, while for a molecular weight of $5 \mathrm{kDa}$, it is $6.0 \mathrm{~nm}$. For a $50 \mathrm{~nm}$ spherical NP with a surface area of $7854 \mathrm{~nm}^{2}$, if $2 \mathrm{kDa}$ molecules were to take on a brush configuration grafted a maximum of $3.5 \mathrm{~nm}$ apart (1 PEG molecule per $(3.5 \mathrm{~nm})^{2}$ or $\left.12.25 \mathrm{~nm}^{2}\right)$, at least 641 molecules are required per NP. Similarly, $5 \mathrm{kDa}$ molecules require 1 PEG molecule per $36 \mathrm{~nm}^{2}$ or 218 molecules per NP. However, it was found that a minimum density of $1 \mathrm{PEG} / \mathrm{nm}^{2}$ is required to achieve a significant reduction in nonspecific protein adsorption. ${ }^{22,26}$

One of such proteins that the NP surface is protected from is opsonin. $18,22,26,27$

Opsonin marks NPs for macrophage detection followed by their clearance from the body. With PEGylation, NPs may evade the immune system, achieving longer blood circulation times. This in turn allows higher chances of NP entry and retention in tumor tissue, since such an environment has leaky capillaries and irregular lymphatic structures leading to the enhanced permeability and retention (EPR) effect. $^{10,28}$ The EPR effect is taken advantage of by PEG-coated liposomes used in chemotherapy, since it allows preferential accumulation of NPs in the tumor. ${ }^{3,29}$ PEG-coated liposomes sized 100-200 nm are currently used as delivery vehicles for FDA-approved chemotherapeutic drugs like doxorubicin and oncospar. ${ }^{3,29}$ It was the 
effectiveness of PEG in this respect that motivated the study of other biocompatible NPs, such as GNPs.

\section{$\underline{1.3 \text { Improved uptake of PEG-coated NPs }}$}

To improve the cellular internalization of PEG-coated NPs, previous studies explored its functionalization with endocytosis-enhancing ligands, such as Herceptin and peptides. ${ }^{30,31}$ For example, Liu et al. showed that RME-peptide and PEG-coated GNPs with a core diameter of $10 \mathrm{~nm}$ had enhanced uptake in HeLa cells in vitro in comparison to GNPs coated with PEG alone. ${ }^{31}$ Similarly, Herceptin-functionalized $50 \mathrm{~nm}$ GNPs backfilled with PEG were found to have higher SKBR3-targeting specificity and lower non-specific protein adsorption. ${ }^{30}$ These promising findings imply that an understanding of cell-targeting PEG-coated NPs is necessary in order to move forward with NP-based medical treatments like chemotherapy and radiation therapy.

\subsection{GNPs for cancer therapy}

The use of inorganic NPs is of interest as they are easily synthesized and designed, especially in the case of GNPs whose physical and chemical properties are easily modifiable. ${ }^{16,32}$ For example, the citrate reduction method of synthesis more popularly known as the Turkevich method only requires varying concentrations of sodium citrate to vary GNP size. ${ }^{33}$ Surface modification may also be done easily via electrostatic attraction, chemisorption, and displacement of surface bound ligands. 16 However, unlike liposomes and as with other inorganic NPs, GNPs need surface 
ligands for cellular internalization, since inorganic NPs enter cells by receptor mediated endocytosis (RME). ${ }^{1,2}$ Citrate-coated GNPs synthesized from the Turkevich method accomplish this by nonspecific adsorption of proteins in serum, which facilitate RME (Figure 1.3). These proteins interact with cell membrane receptors, allowing endocytosis. The contents of the endosome is then sorted so that receptors are recycled back to the cell membrane and GNPs fuse with the lysosome for its transport back to the cell membrane for exocytosis. PEG minimizes GNP surface exposure to its environment, reducing the amount of surface protein on GNPs. Because of this, PEG-coated GNPs are found to have decreased cellular uptake in vitro. $^{34}$ Nativo et al found that PEG-coated GNPs had significantly less uptake by HeLa cells. Similarly, Arnida et al found the same trend using PC-3 cells. ${ }^{34}$ These in vivo studies suggest that PEG-coated GNPs localize external to cancer cells in interstitial tissue. Chemotherapeutic toxicity relies on the entry of drugs into cancer cells. $^{35} \mathrm{NP}$ cellular uptake was also found to correlate with sensitization of cancer cells to radiation therapy. ${ }^{36}$ It may be considered favorable to minimize the volume of unused inorganic NPs in the body because such particles accumulate in immune system organs, causing side effects that include kidney and liver failure. A balance between cancer cell uptake and NP stealth from the immune system by avoiding nonspecific protein adsorption is required.

\subsection{Hypothesis and objectives}

It is known how the size of the NPs affect uptake of as-made NPs. However, it is not fully understood how the core size of NPs affects cell uptake 
in vitro once coated with PEG and cell-targeting ligands. Understanding this property of modified NPs is important for their applications in therapeutic applications. The goals of this study are as follows (Figure 1.4).

- To observe the effect of core size on uptake of cell-targeting and PEG-coated NPs using GNPs as a model system.

- To show the cell line dependence of cancer cell entry of such surfacemodified NPs.

\subsection{References}

1 B. D. Chithrani, " Intracellular uptake, transport, and processing of gold nanostructures," Mol Membr Biol 27, 299-311 (2010).

2 B. D. Chithrani, "Optimization of Bio-Nano Interface Using Gold Nanostructures as a Model Nanoparticle System," Insciences J 1, 136-156 (2011).

3 D. B. Chithrani, "Nanoparticles for Improved therapeutics and Imaging in Cancer Therapy," Recent Pat. Nanotechnol. 4, 171-180 (2010).

4 S. Jelveh and D. B. Chithrani, "Gold Nanostructures as a Platform for Combinational Therapy in Future Cancer Therapeutics," Cancers 3, 10811110 (2011).

5 R. Singh and H. S. Nalwa, "Medical applications of nanoparticles in biological imaging, cell labeling, antimicrobial agents, and anticancer nanodrugs," J Biomed Nanotechnol 7 (4), 489-503 (2011); M. N. V. Ravi

Kumar, M. Sameti, C. Kneuer, A. Lamprecht, and C. M. Lehr, "Polymeric 
nanoparticles for drug and gene delivery", in Encyclopedia of Nanoscience and Nanotechnology, edited by H. S. Nalwa (American Scientific Publishers, Los Angeles, CA, 2004), Vol. 9, pp. 1-19; E. Nakache, N. Poulain, F. Candau, A. M. Orecchioni, and J. M. Irache, "Biopolymer and polymer nanoparticles and their biomedical applications", in Handbook of nanostructured materials and nanotechnology, edited by H. S. Nalwa (Academic Press, San Diego, CA, 2000), Vol. 5, pp. 577-635.

6 A. G. Cuenca, H. Jiang, S. N. Hochwald, M. Delano, W. G. Cance, and S. R. Grobmyer, "Emerging implications of nanotechnology on cancer diagnostics and therapeutics," Cancer 107, 459-466. (2006); T. S. Hauck, J.L. Jennings, T. Yatsenko, J.C. Kumaradas, and W. C. W. Chan, "Enhancing the Toxicity of Cancer Chemotherapeutics with Gold Nanorod Hyperthermia," Adv Mater 20, 3832-3838 (2008); J. Rao, "Shedding Light on Tumors Using Nanoparticles," ACS Nano 2, 1984-1986 (2008).

7 T. Zhan, P. Li, S. Bi, B. Dong, H. Song, H. Ren, and L. Wang, "12Pconjugated PEG-modified gold nanorods combined with near-infrared laser for tumor targeting and photothermal therapy," Journal of nanoscience and nanotechnology 12 (9), 7198-7205 (2012).

$8 \quad$ P. Alivisatos, "The use of nanocrystals in biological detection.," Nat. Biotech. 22, 47-51 (2003); M. Liong, J. Lu, M. Kovochich, T. Xia, S. G. Ruehm, A. E. Nel, F. Tamanoi, and J. I. Zink, "Multifunctional Inorganic Nanoparticles for Imaging, Targeting, and Drug Delivery," ACS Nano 2, 889-896. (2008); S. D. Perrault, C. Walkey, T. Jennings, H. C. Fischer, and W. C. W. Chan, 
"Mediating Tumor Targeting Efficiency of Nanoparticles Through Design," Nano Lett. 9, 1909-1915. (2009).

9 Y. Ding, Y.Y. Zhou, H. Chen, D.D. Geng, D.Y. Wu, J. Hong, W.B. Schen, T.J. Hang, and C. Zhang, "The performance of thiol-terminated PEGpaclitaxel-conjugated gold nanoparticles," Biomaterials 34, 10217-10227 (2013).

10 S.D. Li and L.S. Huang, "Stealth nanoparticles: High density but sheddable PEG is a key for tumor targeting.," J Control Release. 145, 178-181 (2010).

11 X.D. Zhang, D. Wu, P.X. Liu, N. Yang, B. Zhao, H. Zhang, Y.M. Sun, L.N. Zhang, and F.Y. Fan, "Size-dependent in vivo toxicity of PEG-coated gold nanoparticles," Int J Namomed 6, 2071-2081 (2011); Y. Akiyama, i T. Mor, Y. Katayama, and T. Niidome, "The effects of PEG grafting level and injection dose on gold nanorod biodistribution in the tumor-bearing mice," $\mathrm{J}$ Control Release. 139, 81-84 (2009).

12 W.S. Cho, M. Cho, J. Jeong, M. Choi, B.S. Han, H.S. Shin, B.H. Hong, B.H. Chung, J. Jeong, and M.H. Cho, "Size-dependent tissue kinetics of PEGcoated gold nanoparticles," Toxicol Appl Pharmacol 245, 116-123 (2010).

13 T. Maldiney, C. Richard, J. Seguin, N. Wattier, M. Bessodes, and D. Scherman, "Effect of core diameter, surface coating, and PEG chain length on the biodistribution of persistent luminescence nanoparticles in mice," ACS Nano 5, 854-862 (2011).

14 R. Dharmatti, C. Phadke, A. Mewada, S. Pandey, G. Oza, C. Sharon, and M. Sharon, "Surface Orchestration of Gold Nanoparticles Using Cysteamine as 
Linker and Folate as Navigating Molecule for Synaphic Delivery of Doxorubicin," Journal of Nanomedicine Research 1 (1), 00002 (2014).

15 M. Malekigorji, A. D. M. Curtis, and C. Hoskins, "Use of Iron Oxide Nanoparticles for Pancreatic Cancer Therapy," Journal of Nanomedicine Research 1 (1), 12 (2014); G. Y. Lee, W. P. Qian, L. Wang, Y. A. Wang, C. A. Staley, M. Satpathy, S. Nie, H. Mao, and L. Yang, "Theranostic nanoparticles with controlled release of gemcitabine for targeted therapy and MRI of pancreatic cancer," ACS nano 7 (3), 2078-2089 (2013).

D. Yohan and D. B. Chithrani, "Applications of Nanoparticles in Nanomedicine " J. Biomed. Nanotechnol. 10, 2371-2392 (2014).

17 W.S. Cho, M. Cho, J. Jeong, M. Choi, H.Y. Cho, B.S. Han, S.H. Kim, H.O. Kim, Y.T. Lim, B.H. Chung, and J. Jeong, "Acute toxicity and pharmacokinetics of $13 \mathrm{~nm}$-sized PEG-coated gold nanoparticles," Toxicol Appl Pharmacol 236, 16-24 (2009).

18 N. Khlebtsov and L. Dykman, "Biodistribution and toxicity of engineered gold nanoparticles: A review of in vitro and in vivo studies," Chem Soc Rev 40, 1647-1671. (2011).

19 J. Lipka, M. Semmler-Behnke, R.A. Sperling, A. Wenk, S. Takenaka, C. Schleh, T. Kissel, W. J. Parak, and W.G. Kreyling, "Biodistribution of PEGmodified gold nanoparticles following intratracheal instillation and intravenous injection," Biomaterials, 6574-6581 (2010).

20 F. Geng, J. Z. Xing, J. Chen, R. Yang, Y. Hao, K. Song, and B. Kong, "Pegylated glucose gold nanoparticles for improved in-vivo bio-distribution 
and enhanced radiotherapy on cervical cancer," J Biomed Nanotechnol 10 (7), 1205-1216 (2014).

21 Y. Hu, J. Xie, Y.W. Tong, and C.H. Wang, "Effect of PEG conformation and particle size on the cellular uptake efficiency of nanoparticles with the HepG2 cells.," J Control Release. 118, 7-17 (2007).

22 C. D. Walkey, J. B. Olsen, H. Guo, A. Emili, and W. C. Chan, "Nanoparticle size and surface chemistry determine serum protein adsorption and macrophage uptake," J Am Chem Soc 134 (4), 2139-2147 (2012).

23 K. Rahme, L. Chen, R. G. Hobbs, M. A. Morris, C. O'Driscoll, and J. D. Holmes, "PEGylated gold nanoparticles: polymer quantification as a function of PEG lengths and nanoparticle dimensions," RSC Advances 3, 10 (2013); J. V. Jokerst, T. Lobovkina, R. N. Zare, and S. S. Gambhir, "Nanoparticle PEGylation for imaging and therapy," Nanomedicine 6 (4), 715-728 (2011).

24 P. G. Degennes, "Polymers at an interface; a simplified view," Advances in Colloid and Interface Science 27 (3-4), 21 (1987).

25 A. R. Nicholas, M. J. Scott, N. I. Kennedy, and M. N. Jones, "Effect of grafted polyethylene glycol (PEG) on the size, encapsulation efficiency and permeability of vesicles," Biochimica et biophysica acta 1463 (1), 167-178 (2000).

26 T.A. Larson, P.P. Joshi, and K. Sokolov, "Preventing Protein Adsorption and Macrophage Uptake of Gold Nanoparticles via a Hydrophobic Shield," ACS Nano 6, 9182-9190 (2012). 
27 Arnida, M. M. Janat-Amsbury, A. Ray, C. M. Peterson, and H. Ghandehari, "Geometry and surface characteristics of gold nanoparticles influence their biodistribution and uptake by macrophages," Eur J Pharm Biopharm 77 (3), 417-423 (2011).

28 A.N. Gordon, C.O. Granai, P.G. Rose, J. Hainsworth, A. Lopez, C. Weissman, R. Rosales, and T. Sharpington, "Phase II study of liposomal doxorubicin in platinum- and paclitaxel-refractory epithelial ovarian cancer," J Clin Oncol, 3093-3100 (2000).

29 R.A. Petros and J.M. DeSimone, "Strategies in the design of nanoparticles for therapeutic applications," Nat Rev Drug Discov 9, 615-627 (2010).

30 Q. Dai, C. Walkey, and W. C. Chan, "Polyethylene glycol backfilling mitigates the negative impact of the protein corona on nanoparticle cell targeting," Angew Chem Int Ed Engl 53 (20), 5093-5096 (2014).

31 Y. Liu, M. K. Shipton, J. Ryan, E. D. Kaufman, S. Franzen, and D. L. Feldheim, "Synthesis, stability, and cellular internalization of gold nanoparticles containing mixed peptide-poly(ethylene glycol) monolayers," Anal Chem 79 (6), 2221-2229 (2007).

32 C. Yang, M. Neshatian, and M. van Prooijen, "Cancer nanotechnology: enhanced therapeutic response using peptide-modified gold nanoparticles," Journal of nanoscience and nanotechnology 14 (7), 4813-4819 (2014); A. J. Mieszawska, W. J. Mulder, Z. A. Fayad, and D. P. Cormode, "Multifunctional gold nanoparticles for diagnosis and therapy of disease," Molecular pharmaceutics 10 (3), 831-847 (2013). 
33 G. Frens, "Controlled nucleation for the particle size in monodisperse gold suspensions," Nature Physical Science 241, 20-22 (1973).

34 P. Nativo, I. A. Prior, and M. Brust, "Uptake and intracellular fate of surfacemodified gold nanoparticles," ACS Nano 2 (8), 1639-1644 (2008); R. Levy, U. Shaheen, Y. Cesbron, and V. See, "Gold nanoparticles delivery in mammalian live cells: a critical review," Nano Rev 1 (2010); $\quad$ M. Eghtedari, A. V. Liopo, J. A. Copland, A. A. Oraevsky, and M. Motamedi, "Engineering of hetero-functional gold nanorods for the in vivo molecular targeting of breast cancer cells," Nano Lett 9 (1), 287-291 (2009); C. J. Liu, C. H. Wang, C. C. Chien, T. Y. Yang, S. T. Chen, W. H. Leng, C. F. Lee, K. H. Lee, Y. Hwu, Y. C. Lee, C. L. Cheng, C. S. Yang, Y. J. Chen, J. H. Je, and G. Margaritondo, "Enhanced x-ray irradiation-induced cancer cell damage by gold nanoparticles treated by a new synthesis method of polyethylene glycol modification," Nanotechnology 19 (29), 295104 (2008).

35 N. Kohler, C. Sun, J. Wang, and M. Zhang, "Methotrexate-modified superparamagnetic nanoparticles and their intracellular uptake into human cancer cells," Langmuir: the ACS journal of surfaces and colloids 21 (19), 8858-8864 (2005); P. Podsiadlo, V. A. Sinani, J. H. Bahng, N. W. Kam, J. Lee, and N. A. Kotov, "Gold nanoparticles enhance the anti-leukemia action of a 6-mercaptopurine chemotherapeutic agent," Langmuir: the ACS journal of surfaces and colloids 24 (2), 568-574 (2008).

36 D. B. Chithrani, S. Jelveh, F. Jalali, M. van Prooijen, C. Allen, R. G. Bristow, R. P. Hill, and D. A. Jaffray, "Gold nanoparticles as radiation sensitizers in 
cancer therapy," Radiat Res 173 (6), 719-728 (2010); B. D. Chithrani and W. C. Chan, "Elucidating the mechanism of cellular uptake and removal of protein-coated gold nanoparticles of different sizes and shapes," Nano Lett 7 (6), 1542-1550 (2007); W. Chen and J. Zhang, "Using nanoparticles to enable simultaneous radiation and photodynamic therapies for cancer treatment," Journal of nanoscience and nanotechnology 6 (4), 1159-1166 (2006); S. H. Cho, "Estimation of tumor dose enhancement due to gold nanoparticles during typical radiation treatments: a preliminary Monte Carlo Study.," Phys. Med. Biol. 50, N163-N173. (2005). 


\section{$\underline{1.7 \text { Figures }}$}

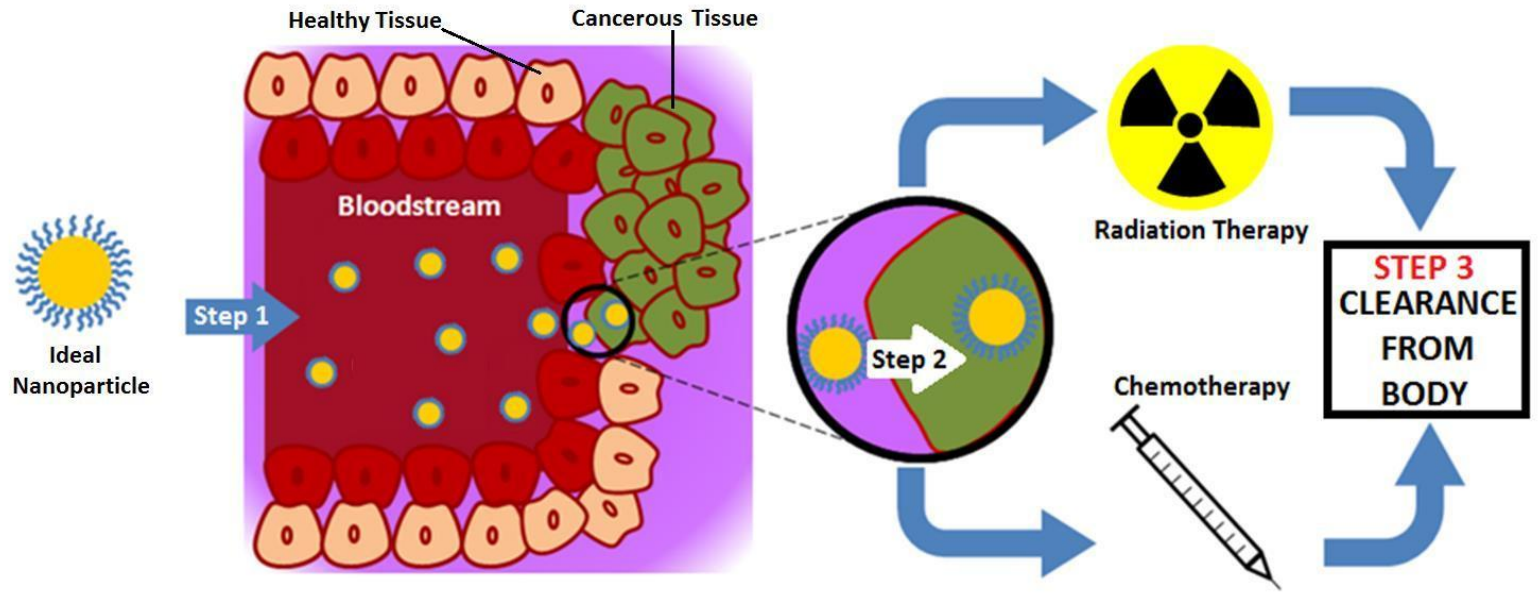

Figure 1.1 Characteristics of an ideal nanoparticle system. Prolonged in vivo residency time is the primary requirement for a successful NP system. This allows higher chances of tumor environment entry prior to clearance from the body. Following this criteria, preferential localization in tumor environments and cancer cell internalization are ideal for applications that favor intracellular localization. Finally, after performing its function, its clearance from the body is ideal. 


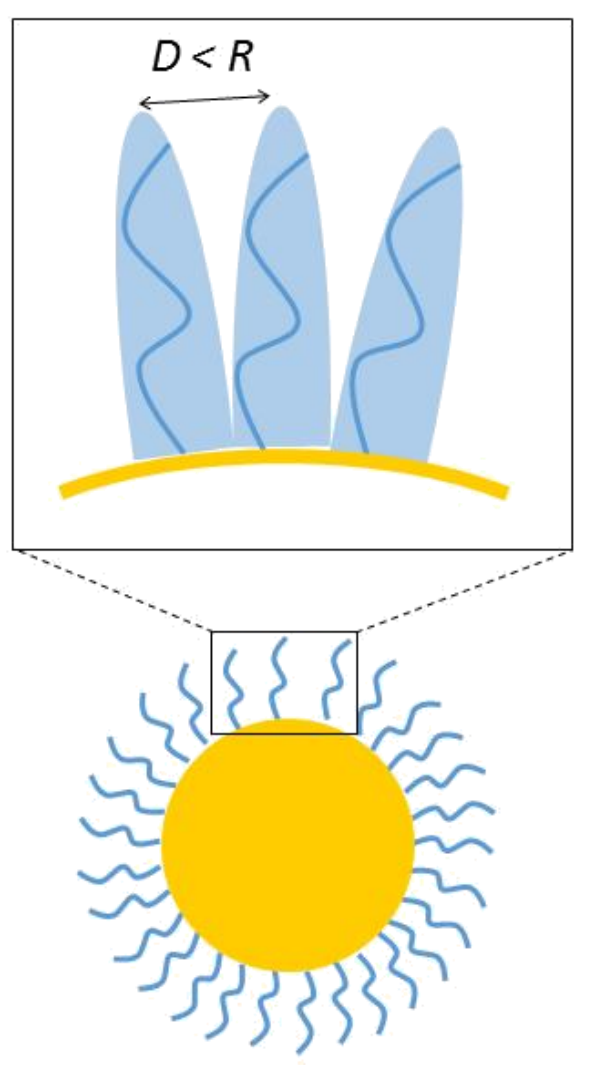

Brush
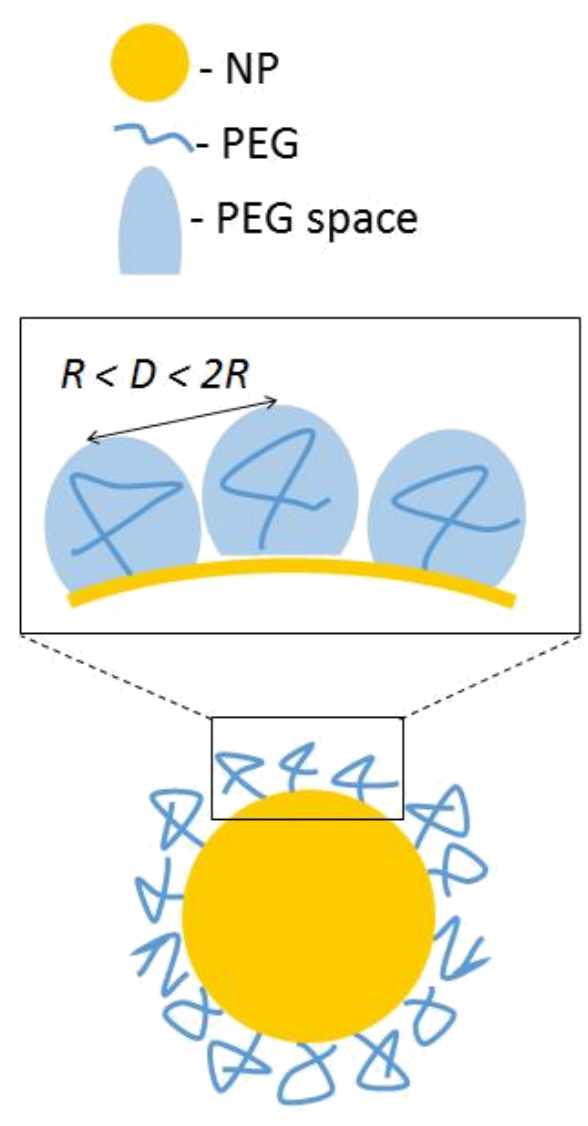

Mushroom

Figure 1.2 PEG conformation on NP surface depends on grafting density. High density PEG is grafted at a distance $D$ less than a Flory radius $R$ from each other as calculated by equation 1 . These display what is referred to as a brush conformation. On the other hand, with lower density PEG, where $R<D<2 R$, a mushroom conformation is achieved. 

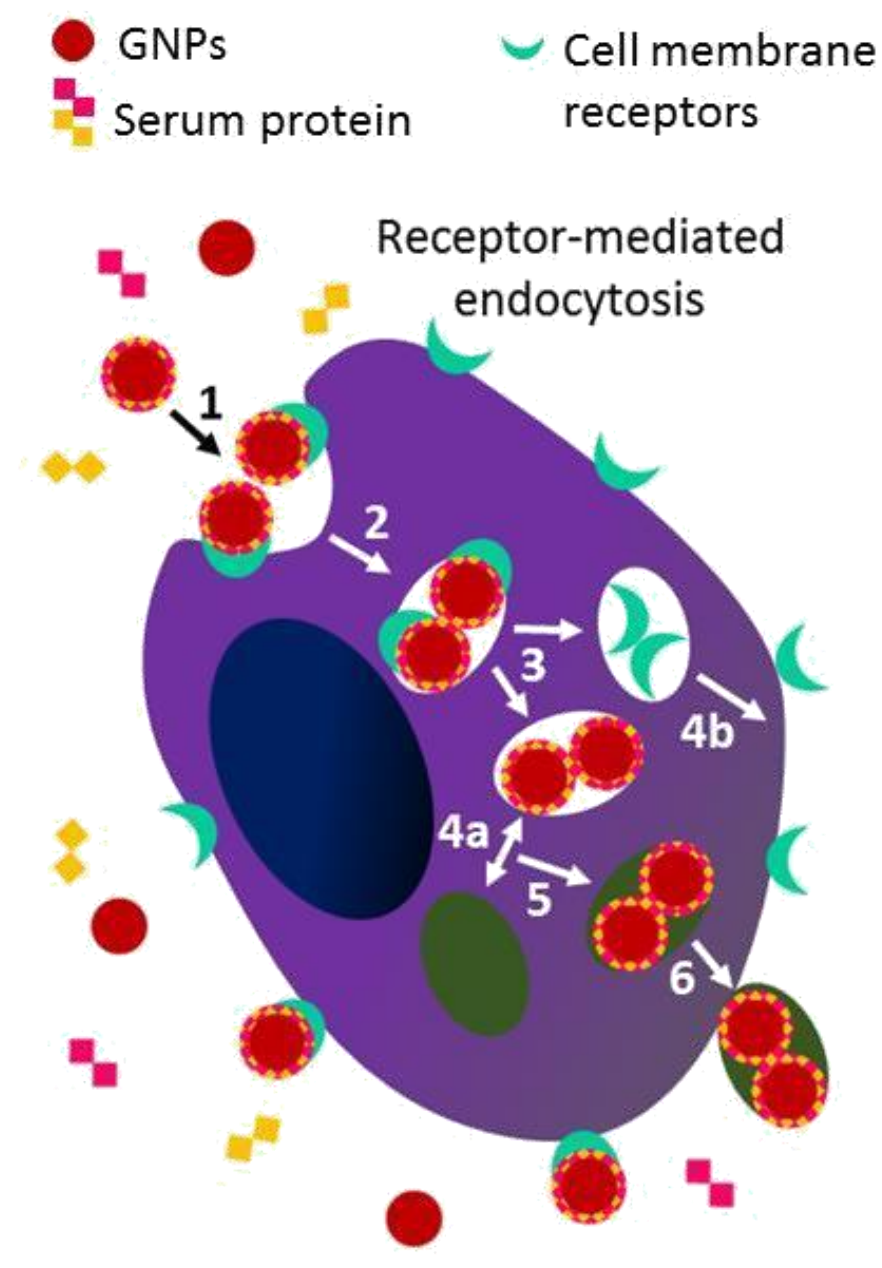

Figure 1.3 The RME process of GNP entry into cells. GNPs nonspecifically adsorb serum protein, which facilitate RME. The events are as follows as labelled above. 1 interaction with cell membrane receptor, 2 - endocytosis, 3 - sorting, $4 \mathrm{a}$ - fusion with lysosome, $4 \mathrm{~b}$ - recycling of receptors, 5 - transport to cell membrane, 6 - exocytosis. 
Cancer Cell Entry

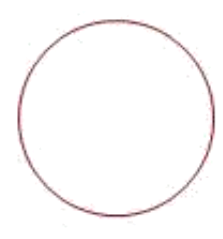

No GNP

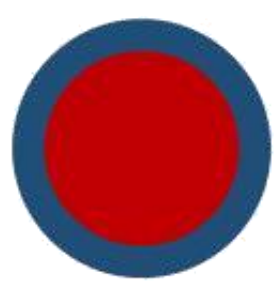

PEG-GNP

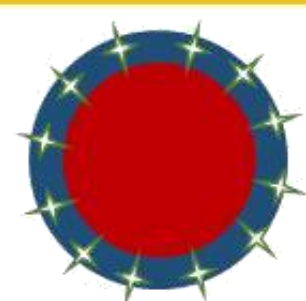

Cell-targeting PEG-GNP

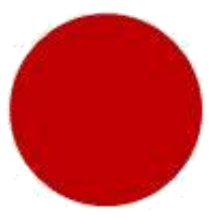

Unmodified GNP

\section{Therapeutic Effect}

Figure 1.4 Hypothesis on improved therapeutic effect due to GNPs and enhanced cancer cell entry of surface-modified GNPs. The therapeutic effect of radiation therapy has been found to improve with the cancer cell entry of GNPs, which is the motivation of this study. Previous studies used unmodified GNPs, which is quickly cleared by the body prior to tumor localization. In addition to unmodified GNPs, surface-modified GNPs are also used in this study. 


\title{
CHAPTER 2
}

\section{INTEGRATION OF PEPTIDES FOR ENHANCED \\ UPTAKE OF PEGYLATED \\ GOLD NANOPARTICLES}

\author{
C. Cruje and B. D. Chithrani
}

\subsection{Preface}

This chapter is a manuscript that was submitted to the American Scientific Publishers for the Journal of Nanoscience and Nanotechnology.

\section{$\underline{2.2 \text { Abstract }}$}

Polyethylene glycol (PEG) has promoted the prospective applications of nanoparticles (NPs) in cancer therapy. PEG is used to evade the immune system allowing NP accumulation within the tumour using its leaky vasculature. However, the cellular uptake of PEG-coated (PEGylated) NPs is lower in comparison to nonPEGylated NPs since PEG minimizes surface binding of ligands that mediate NP endocytosis. For improved outcome in therapeutic applications, it is necessary to enhance the uptake of PEGylated NPs. We added a peptide containing an integrin 
binding domain known as the RGD sequence to the NP surface in addition to PEG. We used gold NPs (GNPs) of sizes 14, 50, and $70 \mathrm{~nm}$ in this study. Our in vitro data for HeLa cells show enhanced uptake for NPs coated with both PEG and the peptide in comparison to PEGylated GNPs. NPs of size $50 \mathrm{~nm}$ had the highest uptake among the three sizes for all GNP surfaces. A similar size-dependent trend was observed for MDA-MB-231 cells for as-made GNPs with lower uptake in comparison to HeLa cells, though only $14 \mathrm{~nm}$ NPs had enhanced uptake. Hence, NP uptake was found dependent on cell type and NP surface properties. A properly designed NP system with both PEG and cell membrane targeting peptides can be used to protect it from the immune system and promote internalization by cells upon entry into tumour environment.

\subsection{Keywords}

Gold Nanoparticles, Peptides, Polyethylene glycol, cancer cells, cellular uptake.

\subsection{Introduction}

Progress in the biomedical research of NPs has developed NP-based cancer therapeutics and imaging. ${ }^{1-4}$ Nanotechnology encourages innovations of safer yet more effective options for disease management. ${ }^{2,4,5}$ Targeted delivery of therapeutics to tumours while causing minimum damage to normal tissue and side effects is the goal of such NP platforms. ${ }^{6}$ Ideal NP systems require prolonged blood circulation times, favourably enter tumour environments, and preferably enter cancer cells for applications that improve with intracellular localization (Figure 2.1). ${ }^{7,8}$ Prolonged 
blood circulation may be considered the most vital constraint as without it, NPs may be cleared from the body prior to performing its function. To accomplish this, NPs have been synthesized into specific sizes and surfaces to promote favourable in vivo blood circulation times and biodistribution. ${ }^{9,10}$ Nanoparticles must have long blood circulation times for higher chances of entering the tumour environment. In vivo studies have shown that such is achieved via NP surface modification with PEG. PEG is the most used molecule in promoting the stealth nature of NPs from the immune system, hence prolonging blood circulation times. ${ }^{11,12}$ PEG creates a hydrophilic layer around the NP, buffering the NP from the environment. ${ }^{7,10,11,13,14}$ High-density PEGylated NPs will have decreased NP surface exposure to serum proteins. ${ }^{12,14,15}$ A type of these proteins is opsonin, which marks NPs for macrophage clearance from the body. Hence, longer blood circulation times are achieved. There is increased chances of NP entry and retention in tumour environments due to leaky tumour capillaries and irregular lymphatic structures. ${ }^{8,16}$ This is termed as the enhanced permeability and retention (EPR) effect, and such allows preferential accumulation of NPs in the tumour. ${ }^{17}$ The EPR effect is taken advantage of by PEGylated liposomes used in chemotherapy. ${ }^{3,18}$ Liposomes that are PEGylated and sized 100-200 $\mathrm{nm}$ are used to deliver FDA-approved chemotherapeutic drugs like doxorubicin and oncospar. ${ }^{3,18}$ The efficiency of such PEGylated liposomes in chemotherapy treatments promoted the investigation of other biocompatible NP systems, such as GNPs. Compared to liposomes, inorganic NP systems are easier to synthesize and design, especially in the case of GNPs whose size and surface are easily modified. The citrate 
reduction method of synthesis only requires varying concentrations of sodium citrate, which acts as a reducing and coating agent.

Surface modification can also be easily done with chemisorption, electrostatic attraction and displacement of surface bound ligands. However, like other inorganic NPs and unlike liposomes, GNPs require surface ligands to mediate cellular internalization, as inorganic NPs enter cells via receptor mediated endocytosis (RME). ${ }^{1,2}$ As-made GNPs accomplish this through serum protein adsorption, which is minimized by PEG. For this reason, PEGylated GNPs have reduced cancer cell uptake in vitro. ${ }^{19}$ This suggests that in vivo, PEGylated GNPs localize extracellular to cancer cells in tumour interstitial tissue. As shown in Figure 2.1 where an ideal NP system is described, PEGylation of GNPs accomplishes prolonged blood circulation times but decreases internalization by cancer cells. Intracellular localization is important for NP chemotherapeutic toxicity. ${ }^{20}$ Sensitization of cancer cells to radiation therapy has also been found dependent on NP cellular uptake. ${ }^{21}$ Hence, celltargeting PEGylated NPs is ideal for such applications.

To improve the cellular internalization of PEGylated NPs, previous studies explored its functionalization with endocytosis-enhancing ligands, such as Herceptin and peptides. ${ }^{22,23}$ For example, Liu et al. showed that RGD-peptide functionalized PEGylated GNPs with a core diameter of $10 \mathrm{~nm}$ had enhanced uptake in HeLa cells in vitro in comparison to GNPs coated with PEG alone. ${ }^{23}$ 
Similarly, Herceptin-functionalized $50 \mathrm{~nm}$ GNPs backfilled with PEG were found to have higher SKBR3-targeting specificity and lower non-specific protein adsorption. ${ }^{22}$ These promising findings imply that an understanding of cell-targeting PEGylated NPs is necessary in order to move forward with NP-based medical treatments like chemotherapy and radiation therapy. Though it is known how the size of the NPs affect uptake of non-PEGylated NPs, it is not yet known how the core size of NPs affects cell uptake in vitro once PEGylated and/or functionalized with cell-targeting ligands. Understanding this property of modified NPs is important because such NPs are ones that are applicable in vivo. Hence, we studied the uptake of such modified NPs as a function of their core diameter and cell type. By functionalizing NPs with the same number of peptide and PEG molecules, we were able to enhance uptake of PEGylated GNPs by $75 \%$. We have shown that PEG combined with a specific peptide not only enhance uptake, but is also cell specific.

In summary, GNPs of diameters 14,50 and $70 \mathrm{~nm}$ were used as a model system to observe the effect of size on uptake of GNPs that are as-made, PEGylated (PEGGNPs), and cell-targeting and PEGylated (RGD-PEG-GNPs). For cell-targeting, a synthetic peptide, CKKKKKKGGRGDMFG, containing the integrin binding domain known as RGD was used. Integrins are transmembrane glycoproteins used by a number of viruses for cell internalization. ${ }^{24}$ The molecular weight of the peptide is 1669 Da. PEG with a molecular weight of $2 \mathrm{kDa}$ was used, which is clinically applied in liposome systems in chemotherapy. ${ }^{25}$ To assess cell specificity, we used a cervical 
cancer cell line (HeLa cells) and a breast cancer cell line (MDA-MB-231 cells). We were able to qualitatively verify the variation of NP uptake of PEGylated GNPs using the novel CytoViva imaging technique for the first time. This imaging technique not only allows imaging of GNP clusters within the cells, but also provides spectral information. GNPs produce unique high intensity reflectance spectra in comparison to the nucleus, cytoplasm, and other organelles within cells. Such a property allowed CytoViva imaging of GNPs in cells. Results from this study may be used as a guideline in designing clinically efficient inorganic NPs that will enter tumour environments and be internalized by cancer cells effectively.

\section{$\underline{2.5 \text { Materials and methods }}$}

\subsubsection{GNP synthesis}

The citrate reduction method was used to synthesize GNPs of diameters 14 , 50 and $70 \mathrm{~nm} .300 \mathrm{~mL}$ of $1 \% \mathrm{HAuCl} \cdot 3 \mathrm{H} 2 \mathrm{O}$ was added to $30 \mathrm{~mL}$ of distilled water and was brought to a boil while continuously stirring. At boiling point, 700, 113 and $105 \mu \mathrm{L}$ of $1 \%$ anhydrous citric acid was added to synthesize small, medium and large GNPs respectively. For small GNPs, the colour of the solution changed from dark blue to red while for the medium sized and large GNPs, the colour of the solution changed from black to maroon and violet, respectively. All solutions were left to boil for another five minutes while stirring. GNP solutions were brought to room temperature while stirring and then refrigerated. 


\subsubsection{Characterization and PEGylation of GNPs}

GNPs were characterized with UV-visible spectrophotometry, dynamic light scattering (DLS), transmission electron microscopy and zeta potential measurement before PEGylation (Table 2.1). A 1\% PEG solution was prepared with thiolterminated PEG methyl ether with a molecular weight of $2 \mathrm{kDa}$. The solution was added to GNP solutions to achieve a grafting density of 1 PEG molecule per nm ${ }^{2}$. For 14, 50 and $70 \mathrm{~nm}$ GNPs, 616, 7854 and 15394 PEG molecules were added. To confirm PEGylation of GNPs, DLS measurements were done followed by UV-visible spectrophotometry to confirm stability since an increase in diameter is characteristic of GNP PEGylation (Table 2.1).

\subsubsection{Peptide-functionalization of PEG-GNP}

A solution of the peptide molecules with the sequence CKKKKKKGGRGDMFG was mixed with a solution of the PEG molecules at a 1:1 ratio. This was then added to a solution of GNPs. For all conjugates, UV-visible spectrophotometry and DLS was done to confirm minimal shift in size and that no aggregation occurs (Table 2.1). 


\subsubsection{Cellular uptake study}

HeLa cells and MDA-MB-231 were cultured in Dulbecco's Modified Eagle's Medium with $10 \%$ Fetal Bovine Serum grown to confluency so that two $10 \mathrm{~cm}$ culture dishes were incubated with the same NP type per cell line. For optical imaging purposes, MDA-MB-231 cells were placed on glass coverslips and grown to $60 \%$ confluency. All GNP conjugates were incubated with cancer cells for eight hours where an equal amount of NPs were added per cell culture $(1 \mathrm{nM})$. Following incubation, all cell cultures were washed with Phosphate-Buffered Saline (PBS) three times. Those without coverslips were trypsinized and processed for quantification described in the next section. This experiment was repeated three times. Those with coverslips were rinsed twice with PBS, followed by fixation with $4 \%$ paraformaldehyde in PBS for 10 minutes at room temperature, then rehydration in PBS. Coverslips were mounted onto glass slides and were dried overnight for microscopy.

\subsubsection{GNP uptake quantification}

Harvested cells were counted prior to processing for inductively coupled plasma atomic emission spectroscopy (ICP-AES). To prepare samples for ICP-AES, $\mathrm{HNO}_{3}$ was added to samples that were boiled at $200^{\circ} \mathrm{C}$ in an oil bath for cell digestion and GNP atomization. ICP-AES of samples was then performed and resulting gold atom counts were converted to GNPs per cell (Figures 2.2, 2.3 and 2.4). 


\subsubsection{Visual evaluation by CytoViva microscopy}

To qualitatively confirm quantification results from ICP-AES, CytoViva microscopy of cells was done. This imaging system was designed so that despite NP interaction with cells or tissue, their spectra may still be confirmed because they are still optically observable. The microscope is a darkfield imaging system that uses oblique angle lighting. The result is high signal-to-noise optimized darkfield based images. Figure 2.4 and 2.5 shows darkfield images of cells incubated with NPs, which appear bright due to high scattering cross-sections of GNPs. To confirm the spectra of GNPs, Spectral Angle Mapping (SAM) was done with the CytoViva hyperspectral imaging system. SAM determines the presence of GNPs in the input image by comparing unknown spectra in the acquired hyperspectral image to a userdefined spectrum, which is that of a GNP in these experiments.

\subsection{Results and discussion}

\subsubsection{Characterization of citrate-capped (as-made) GNPs}

GNPs of diameters 14,50 and $70 \mathrm{~nm}$ were synthesized via the citrate reduction method as characterized by UV-visible spectrophotometry and DLS as shown in Table 2.1. Red shifts in the peak absorption wavelengths were observed with larger GNPs. The GNP solution with $14 \mathrm{~nm}$ GNPs was red in colour, while the 50 and 70 $\mathrm{nm}$ GNP solutions were maroon and violet coloured respectively. This was because as the size of GNPs increase, surface plasmons of GNPs absorb light of decreasing 
energy or increasing wavelengths. Hence, larger GNPs absorb red shifted light so that some blue light is reflected, resulting in a violet solution. Conversely, smaller GNPs absorb light in the blue to green region of the visible spectrum, causing a red solution.

\subsubsection{PEGylation and RGD peptide functionalization of GNPs}

The PEGylation of GNPs resulted in a slight red shift of peak absorption wavelengths, as observed in Table 2.1. This corresponds to a disturbance in the local refractive index around GNPs due to bound PEG molecules, causing a red shift in the resulting spectra. ${ }^{26}$ DLS measurements confirmed that adding PEG

molecules onto GNPs introduced an average increase of $4.6 \pm 0.6 \mathrm{~nm}$ in hydrodynamic diameter. Hence, GNPs were successfully PEGylated. Preliminary work has shown that functionalization with the peptide alone introduces $1 \mathrm{~nm}$ of hydrodynamic diameter increase. Hence, with the peptide functionalization of PEG-GNPs, red-shifts in spectra remain unchanged. As observed with PEG-GNPs, all RGD-PEG-GNPs peak wavelengths and DLS measurements confirm that stable conjugates were synthesized. Zeta potential measurement showed a clear change in the surface charge of the NPs after functionalization with PEG and RGD. For example it was -13.7, -1.1, and +1.5 for GNPs, PEG-GNPs, and RGD-PEG-GNPs for a core size of $14 \mathrm{~nm}$. 


\subsubsection{Quantification of uptake}

For HeLa cells, $50 \mathrm{~nm}$ NPs had the highest uptake among the three sizes for unmodified GNPs. A similar size-dependent trend was observed for MDA-MB-231 cells for as-made GNPs with lower uptake in comparison to HeLa cells. For HeLa cells, PEG was observed to lower the uptake of 14,50 and $70 \mathrm{~nm}$ GNPs to $26 \%, 29 \%$ and $1 \%$ of same-sized as-made GNPs (Figure 2.2). This was increased by $78 \%, 26 \%$ and $45 \%$ by RGD-functionalization, where the highest enhancement was observed for $14 \mathrm{~nm}$ GNPs (Figure 2.3). For MDA-MB-231 cells, PEG lowered the uptake to $20 \%$, $3 \%$ and 3\% of as-made GNPs respectively. Uptake was enhanced by $46 \%$ for $14 \mathrm{~nm}$ NPs, while no significant change in uptake was observed for other sizes. The synthetic peptide used in our study consists of the integrin binding domain. Integrin binding domains are known to induce cellular uptake by both RGD and phagocytosis, and has been found cell dependent in previous studies. ${ }^{27}$ We believe that the HeLa cell line has an overexpression of integrins in contrast to the MDA-MB-231 cell line for this particular synthetic peptide, hence enhancing the uptake of the NPs. The lower enhancement in uptake observed in MDA-MB-231 cells is due to the peptide acting as a single type of nonspecific protein that may bind with as-made GNPs, facilitating RME. To achieve comparable enhancement in uptake in MDA-MB-231 cells as in HeLa cells, a different type of peptide sequence would have to be used. Using a variety of targeting peptides as opposed to a single type may also be explored. The highest improvement in uptake was observed for $14 \mathrm{~nm}$ NPs for both cell lines. This suggests that despite adding 
the same amount of PEG molecules to achieve the same density for all sizes of NPs, the protective force of the PEG molecules against surface bound peptides interacting with cell membrane receptors was greater for 50 and $70 \mathrm{~nm}$ GNPs than $14 \mathrm{~nm}$ ones. This may be because larger NPs have lower surface curvatures than smaller NPs. Lower surface curvatures lead to less free space between grafted molecules despite constancy in grafting distances. Less free space between PEG molecules minimizes GNP surface interaction with its environment, causing reduced cell membrane receptor access to surface bound peptides. This explains the core size dependence of peptide enhanced cancer cell uptake.

\subsubsection{CytoViva imaging of extracellular and intracellular NPs}

The CytoViva technology was specifically designed for optical observation and spectral confirmation of NPs as they interact with cells and tissues. With the integrated CytoViva hyperspectral imaging capability, reflectance spectra from specific materials can be captured and measured. A sample slide with non-aggregated $14 \mathrm{~nm}$ GNPs and another with aggregated ones were prepared. Spectra from monodispersed (top) and aggregated (bottom) GNPs are shown in the left of Figure 2.4. Reflectance spectra of aggregates showed a distinct red shift. The image panel on the left shows darkfield images of monodisperse and aggregated GNPs (Figure 2.4A-B). Figure $2.4 \mathrm{C}$ shows that the reflectance spectrum from the cytoplasm itself was very low in comparison to GNP clusters localized within the cytoplasm. It can be clearly seen that GNP clusters have very high reflection intensities versus the background. 
Some reflected spectra from GNP clusters localized within cells were collected as shown in Figure 2.4D. The darkfield image of a group of cells with internalized RGD-PEG-GNPs is shown in Figure 2.4E. The GNPs appear bright owing to their high scattering cross-section. Confirmation that such bright-appearing particles were indeed GNPs was done with SAM of the CytoViva system. SAM is an automated procedure used to determine whether GNPs are present in the input image, and locates which pixels contain the material of interest. Figure $2.4 \mathrm{~F}$ shows the hyperspectral image with an overlaid spectral angle map (red dots represent GNPs).

The uptake of NPs with a $14 \mathrm{~nm}$ core size was verified with CytoViva imaging as illustrated in Figure 2.5. Darkfield images of $14 \mathrm{~nm}$ NPs incubated with HeLa and MDA-MB-231 cells were taken with the CytoViva microscope. ICP-AES quantified cellular uptakes generally agree with observed fluorescence. In both cancer cell lines, less fluorescent particles were observed when comparing darkfield images of PEGGNPs to GNPs. On the other hand, more fluorescent particles were observed when comparing darkfield images of RGD-PEG-GNPs to PEG-GNPs. SAM verified that fluorescence observed in darkfield images are indeed GNPs and confirms the general agreement of visual observations with quantified cellular uptake. The peak wavelength of the reflected spectra from GNP clusters within the cell (Figure 2.4D) is very similar to the spectra from aggregated NPs (Figure 2.4B). Gold nanoparticles enter the cell mostly via endocytosis and localize in small vesicles like endosomes and lysosomes. During optical imaging, spectra from a number of 
NPs were collected resulting in a red-shifted broader spectrum. The bright dots we see in the cellular images may not represent single NPs.

\section{$\underline{2.7 \text { Conclusions }}$}

For all NP sizes in HeLa cells, RGD-PEG-GNP uptake was significantly higher in comparison to PEG-GNPs. This shows that the cell-specificity of SKBR3-targeted PEG-GNPs (via Herceptin) also applies for HeLa-targeted PEG-GNPs (via RGD). Previously found for $50 \mathrm{~nm}$ GNPs, our study shows that cell-specificity also applies to smaller or larger NPs as observed for 14 and $70 \mathrm{~nm}$ NPs. It was previously observed that peptide-modified and PEGylated GNPs sized at $10 \mathrm{~nm}$ had improved uptake in comparison to PEG-GNPs. ${ }^{23,38}$

Our study confirmed this finding for comparatively-sized $14 \mathrm{~nm}$ NPs suitable for nuclear targeting. In our study, this was also found applicable to larger nanoparticles sized at 50 and $70 \mathrm{~nm}$ that may be preferred for other clinical applications. Results from our study may serve as a guideline to designing nanoparticles for chemotherapeutic delivery that maximize payload as such an application favours intracellular localization of its delivery system. NP-based radiation therapy sensitizers, which also favour intracellular localization, may also use such results among other clinical NP applications. 


\section{$\underline{2.8 \text { Acknowledgements }}$}

The authors would like to acknowledge the Natural Sciences and Engineering Research Council of Canada (NSERC) and Ryerson University for their financial support.

\subsection{References}

1 B. D. Chithrani, "Intracellular uptake, transport, and processing of gold nanostructures," Mol Membr Biol 27, 299-311 (2010).

2 B. D. Chithrani, "Optimization of Bio-Nano Interface Using Gold Nanostructures as a Model Nanoparticle System," Insciences J 1, 136-156 (2011).

3 D. B. Chithrani, "Nanoparticles for Improved therapeutics and Imaging in Cancer Therapy," Recent Pat. Nanotechnol. 4, 171-180 (2010).

4 S. Jelveh and D. B. Chithrani, "Gold Nanostructures as a Platform for Combinational Therapy in Future Cancer Therapeutics," Cancers 3, 1081$1110(2011)$.

5 A. G. Cuenca, H. Jiang, S. N. Hochwald, M. Delano, W. G. Cance, and S. R. Grobmyer, "Emerging implications of nanotechnology on cancer diagnostics and therapeutics," Cancer 107, 459-466. (2006); T. S. Hauck, J.L. Jennings, T. Yatsenko, J.C. Kumaradas, and W. C. W. Chan, "Enhancing the Toxicity of Cancer Chemotherapeutics with Gold Nanorod Hyperthermia," Adv Mater 20, 3832-3838 (2008); J. Rao, "Shedding Light on Tumors Using Nanoparticles," ACS Nano 2, 1984-1986 (2008). 
6 P. Alivisatos, "The use of nanocrystals in biological detection.," Nat. Biotech. 22, 47-51 (2003); M. Liong, J. Lu, M. Kovochich, T. Xia, S. G. Ruehm, A. E. Nel, F. Tamanoi, and J. I. Zink, "Multifunctional Inorganic Nanoparticles for Imaging, Targeting, and Drug Delivery," ACS Nano 2, 889-896. (2008); S. D. Perrault, C. Walkey, T. Jennings, H. C. Fischer, and W. C. W. Chan, "Mediating Tumor Targeting Efficiency of Nanoparticles Through Design," Nano Lett. 9, 1909-1915. (2009).

7 Y. Ding, Y.Y. Zhou, H. Chen, D.D. Geng, D.Y. Wu, J. Hong, W.B. Schen, T.J. Hang, and C. Zhang, "The performance of thiol-terminated PEGpaclitaxel-conjugated gold nanoparticles," Biomaterials 34, 10217-10227 (2013).

8 S.D. Li and L.S. Huang, "Stealth nanoparticles: High density but sheddable PEG is a key for tumor targeting.," J Control Release. 145, 178-181 (2010).

9 X.D. Zhang, D. Wu, P.X. Liu, N. Yang, B. Zhao, H. Zhang, Y.M. Sun, L.N. Zhang, and F.Y. Fan, "Size-dependent in vivo toxicity of PEG-coated gold nanoparticles," Int J Namomed 6, 2071-2081 (2011); T. Maldiney, C. Richard, J. Seguin, N. Wattier, M. Bessodes, and D. Scherman, "Effect of core diameter, surface coating, and PEG chain length on the biodistribution of persistent luminescence nanoparticles in mice," ACS Nano 5, 854-862 (2011); Y. Akiyama, i T. Mor, Y. Katayama, and T. Niidome, "The effects of PEG grafting level and injection dose on gold nanorod biodistribution in the tumorbearing mice," J Control Release. 139, 81-84 (2009). 
10 W.S. Cho, M. Cho, J. Jeong, M. Choi, B.S. Han, H.S. Shin, B.H. Hong, B.H. Chung, J. Jeong, and M.H. Cho, "Size-dependent tissue kinetics of PEGcoated gold nanoparticles," Toxicol Appl Pharmacol 245, 116-123 (2010).

11 J. Lipka, M. Semmler-Behnke, R.A. Sperling, A. Wenk, S. Takenaka, C. Schleh, T. Kissel, W. J. Parak, and W.G. Kreyling, "Biodistribution of PEGmodified gold nanoparticles following intratracheal instillation and intravenous injection," Biomaterials, 6574-6581 (2010).

12 N. Khlebtsov and L. Dykman, "Biodistribution and toxicity of engineered gold nanoparticles: A review of in vitro and in vivo studies," Chem Soc Rev 40, 1647-1671. (2011).

13 W.S. Cho, M. Cho, J. Jeong, M. Choi, H.Y. Cho, B.S. Han, S.H. Kim, H.O. Kim, Y.T. Lim, B.H. Chung, and J. Jeong, "Acute toxicity and pharmacokinetics of 13 nm-sized PEG-coated gold nanoparticles," Toxicol Appl Pharmacol 236, 16-24 (2009); Y. Hu, J. Xie, Y.W. Tong, and C.H. Wang, "Effect of PEG conformation and particle size on the cellular uptake efficiency of nanoparticles with the HepG2 cells," J Control Release. 118, 717 (2007).

14 C. D. Walkey, J. B. Olsen, H. Guo, A. Emili, and W. C. Chan, "Nanoparticle size and surface chemistry determine serum protein adsorption and macrophage uptake," J Am Chem Soc 134 (4), 2139-2147 (2012).

15 T.A. Larson, P.P. Joshi, and K. Sokolov, "Preventing Protein Adsorption and Macrophage Uptake of Gold Nanoparticles via a Hydrophobic Shield," ACS Nano 6, 9182-9190 (2012); K. Rahme, L. Chen, R.G. Hobbs, M.A. Morris, 
C. O'Driscoll, and J.D. Holmes, "PEGylated Gold Nanoparticles: Polymer Quantification as a Function of PEG lengths and Nanoparticle Dimensions," RSC Adv 3, 6085-6094 (2013); Arnida, M. M. Janat-Amsbury, A. Ray, C. M. Peterson, and H. Ghandehari, "Geometry and surface characteristics of gold nanoparticles influence their biodistribution and uptake by macrophages," Eur J Pharm Biopharm 77 (3), 417-423 (2011).

16 A.N. Gordon, C.O. Granai, P.G. Rose, J. Hainsworth, A. Lopez, C. Weissman, R. Rosales, and T. Sharpington, "Phase II study of liposomal doxorubicin in platinum and paclitaxel refractory epithelial ovarian cancer," J Clin Oncol, 3093-3100 (2000).

17 Cattel L, Ceruti M, and Dosio F., "From conventional to stealth liposomes: a new frontier in cancer chemotherapy," Tumori 89, 237-249 (2003).

18 R.A. Petros and J.M. DeSimone, "Strategies in the design of nanoparticles for therapeutic applications," Nat Rev Drug Discov 9, 615-627 (2010).

19 P. Nativo, I. A. Prior, and M. Brust, "Uptake and intracellular fate of surfacemodified gold nanoparticles," ACS Nano 2 (8), 1639-1644 (2008); R. Levy, U. Shaheen, Y. Cesbron, and V. See, "Gold nanoparticles delivery in mammalian live cells: a critical review," Nano Rev 1 (2010); M. Eghtedari, A. V. Liopo, J. A. Copland, A. A. Oraevsky, and M. Motamedi, "Engineering of hetero-functional gold nanorods for the in vivo molecular targeting of breast cancer cells," Nano Lett 9 (1), 287-291 (2009); C. J. Liu, C. H. Wang, C. C. Chien, T. Y. Yang, S. T. Chen, W. H. Leng, C. F. Lee, K. H. Lee, Y. Hwu, Y. C. Lee, C. L. Cheng, C. S. Yang, Y. J. Chen, J. H. Je, and G. Margaritondo, 
"Enhanced x-ray irradiation-induced cancer cell damage by gold nanoparticles treated by a new synthesis method of polyethylene glycol modification," Nanotechnology 19 (29), 295104 (2008).

B. D. Chithrani, A. A. Ghazani, and W. C. Chan, "Determining the size and shape dependence of gold nanoparticle uptake into mammalian cells," Nano Lett 6 (4), 662-668 (2006).

21 D. B. Chithrani, S. Jelveh, F. Jalali, M. van Prooijen, C. Allen, R. G. Bristow, R. P. Hill, and D. A. Jaffray, "Gold nanoparticles as radiation sensitizers in cancer therapy," Radiat Res 173 (6), 719-728 (2010); B. D. Chithrani and W. C. Chan, "Elucidating the mechanism of cellular uptake and removal of protein-coated gold nanoparticles of different sizes and shapes," Nano Lett 7 (6), 1542-1550 (2007); W. Chen and J. Zhang, "Using nanoparticles to enable simultaneous radiation and photodynamic therapies for cancer treatment," J Nanosci Nanotechnol 6 (4), 1159-1166 (2006); S. H. Cho, "Estimation of tumor dose enhancement due to gold nanoparticles during typical radiation treatments: a preliminary Monte Carlo Study.," Phys. Med. Biol. 50, N163N173. (2005).

22 Q. Dai, C. Walkey, and W. C. Chan, "Polyethylene glycol backfilling mitigates the negative impact of the protein corona on nanoparticle cell targeting," Angew Chem Int Ed Engl 53 (20), 5093-5096 (2014).

23 Y. Liu, M. K. Shipton, J. Ryan, E. D. Kaufman, S. Franzen, and D. L. Feldheim, "Synthesis, stability, and cellular internalization of gold 
nanoparticles containing mixed peptide-poly(ethylene glycol) monolayers," Anal Chem 79 (6), 2221-2229 (2007).

24 S. Hart, R. Harbottle, and C. Coutelle, "Integrin-Mediated Gene Delivery, in Targeting of Drugs 5: Strategies for Oligonucleotide and Gene Delivery in Therapy," Plenum Press, New York London Gregoriadis, G., and McCormack, B., Eds., 101-106 (1995).

25 D.D. Lasic, "Novel applications of liposomes," Trends in Biotechnology 16, $307-321$ (1998).

26 N. Muhammad, N Kryuchkova, T. Dworeck, F. Rodríguez-Ropero, and M. Fioroni, "Enhanced EGFP Fluorescence Emission in Presence of PEG Aqueous Solutions and PIB1000-PEG6000-PIB1000 Copolymer Vesicles," Biomed Res Int. 2013, 329087 (2013).

27 A.G. Tkachenko, Xie. H., Y. Liu, D. Coleman, J. Ryan, W.R. Glomm, M.K. Shipton, S. Franzen, and D.L. Feldheim, "Cellular Trajectories of PeptideModified Gold Particle Complexes: Comparison of Nuclear Localization Signals and Peptide Transduction Domains," Bioconjug. chem. 15, 482-490 (2004). 


\subsection{Tables and figures}

Table 2.1. GNP mean diameter via UV-visible spectra and DLS

\begin{tabular}{|c|c|c|c|c|c|c|}
\cline { 2 - 7 } \multicolumn{1}{c|}{} & \multicolumn{3}{c|}{ Peak Wavelength (nm) } & \multicolumn{3}{c|}{ DLS Mean Diameter (nm) } \\
\hline Surface ligand & 14 & 50 & 70 & 14 & 50 & 70 \\
\hline Citrate & 518 & 532 & 550 & $14.7 \pm 1.7$ & $53.5 \pm 1.3$ & $79.3 \pm 1.1$ \\
\hline PEG & 519 & 533 & 551 & $18.6 \pm 1.3$ & $58.4 \pm 1.4$ & $84.3 \pm 1.6$ \\
\hline RGD-PEG & 519 & 533 & 551 & $18.8 \pm 1.5$ & $59.1 \pm 1.6$ & $84.8 \pm 1.4$ \\
\hline
\end{tabular}




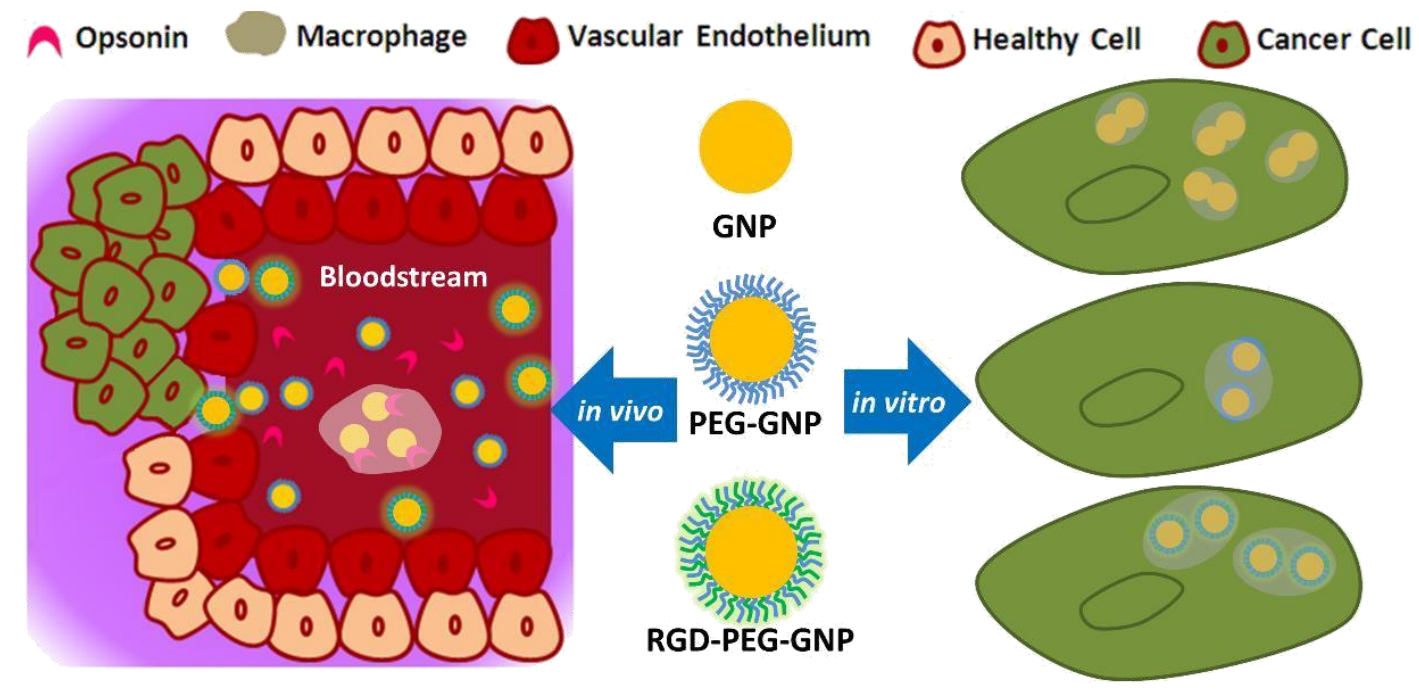

Figure 2.1 Ideal NP design. Prolonged lifetime of NPs in the bloodstream is foremost to its design as such will take advantage of the EPR effect in tumour environments. PEG may be used to accomplish this by repelling opsonin proteins that mark foreign molecules for macrophage binding. For applications that favour intracellular localization, cellular uptake of bloodstream stable nanoparticles must be accomplished. However, in vitro studies show decreased cellular uptake of NPs due to PEG. 

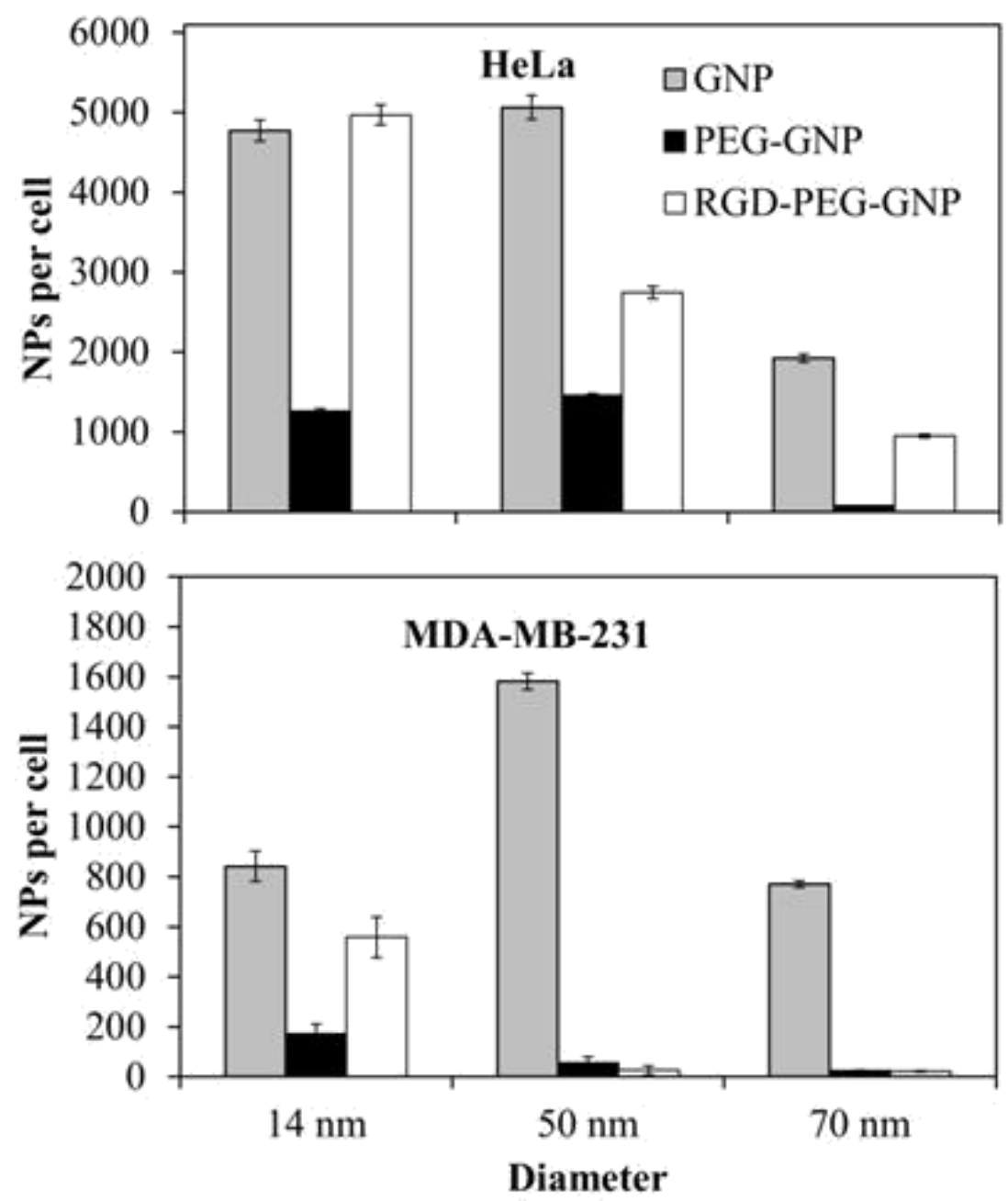

Figure 2.2 Size, surface and cell line dependence of NP cellular uptake in A) HeLa cells and B) MDA-MB-231 cells. 


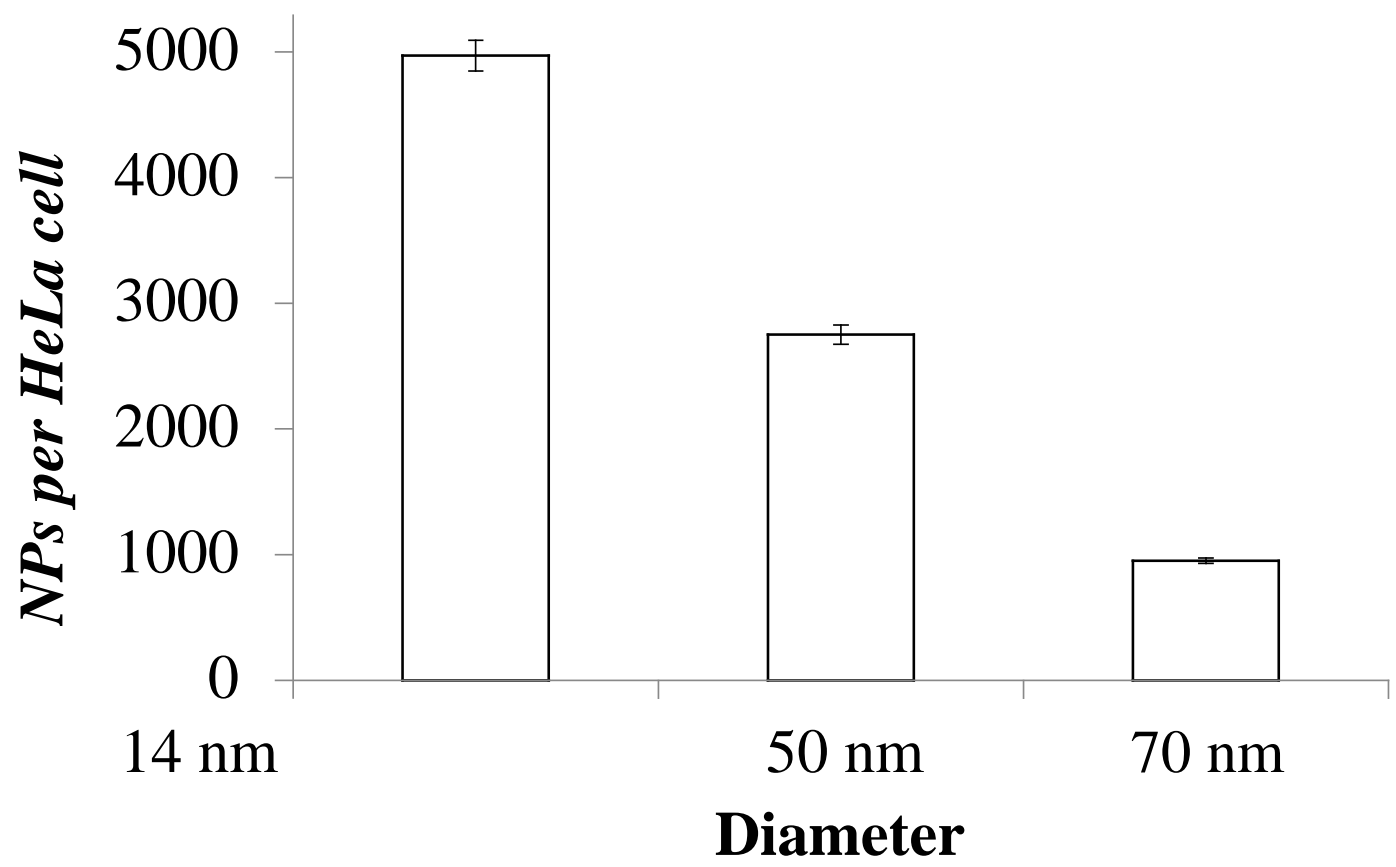

Figure 2.3 Uptake of RGD-PEG functionalized NPs and its dependence on core size. Greatest improvement in cancer cell entry was observed for 14 nm GNPs. 


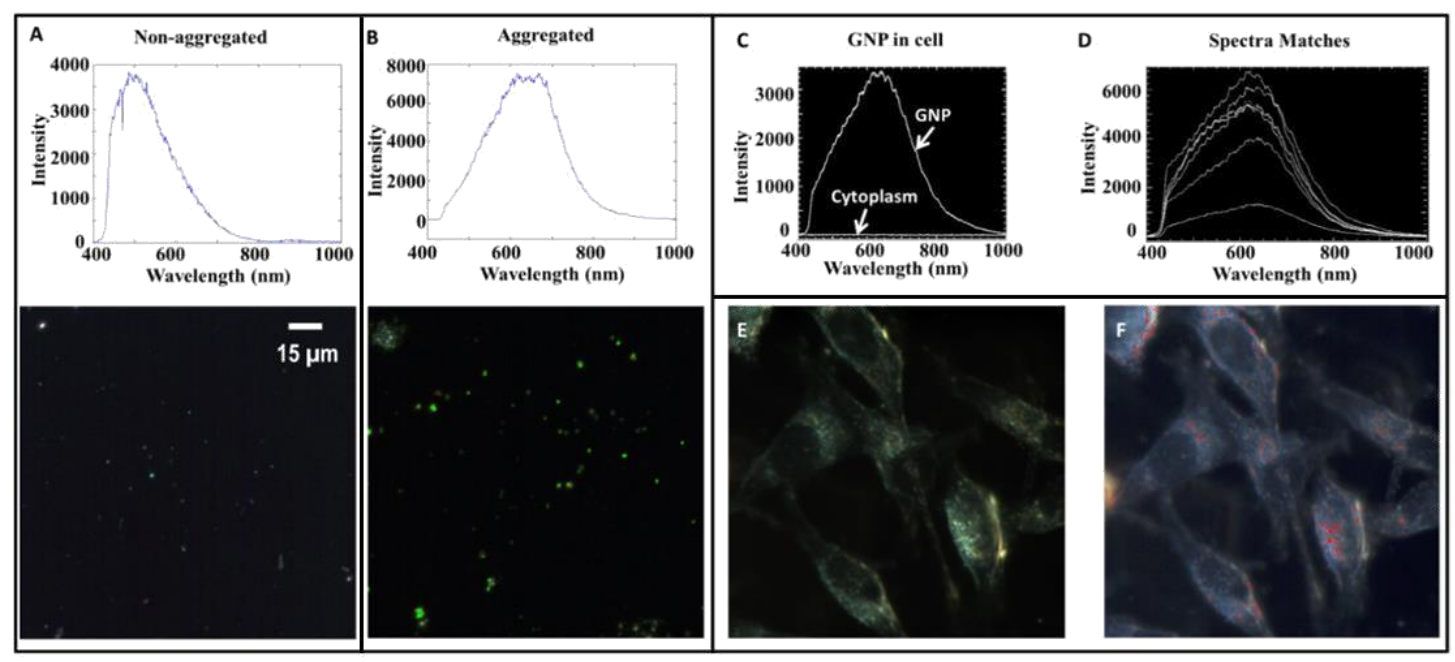

Figure 2.4 Hyperspectral imaging of monodisperse and aggregated GNPs. On the left are reflectance spectra (top) and mapped images based on collected spectra (bottom) of A) monodisperse and B) aggregated GNPs, respectively. SAM reference spectra shown in C) and spectra of D) some matches. E) Darkfield image of 14 nm RGDPEG-GNPs incubated with MDA-MB231 cells and its D) hyperspectral image. The red dots mark matches to reference NP spectra. 

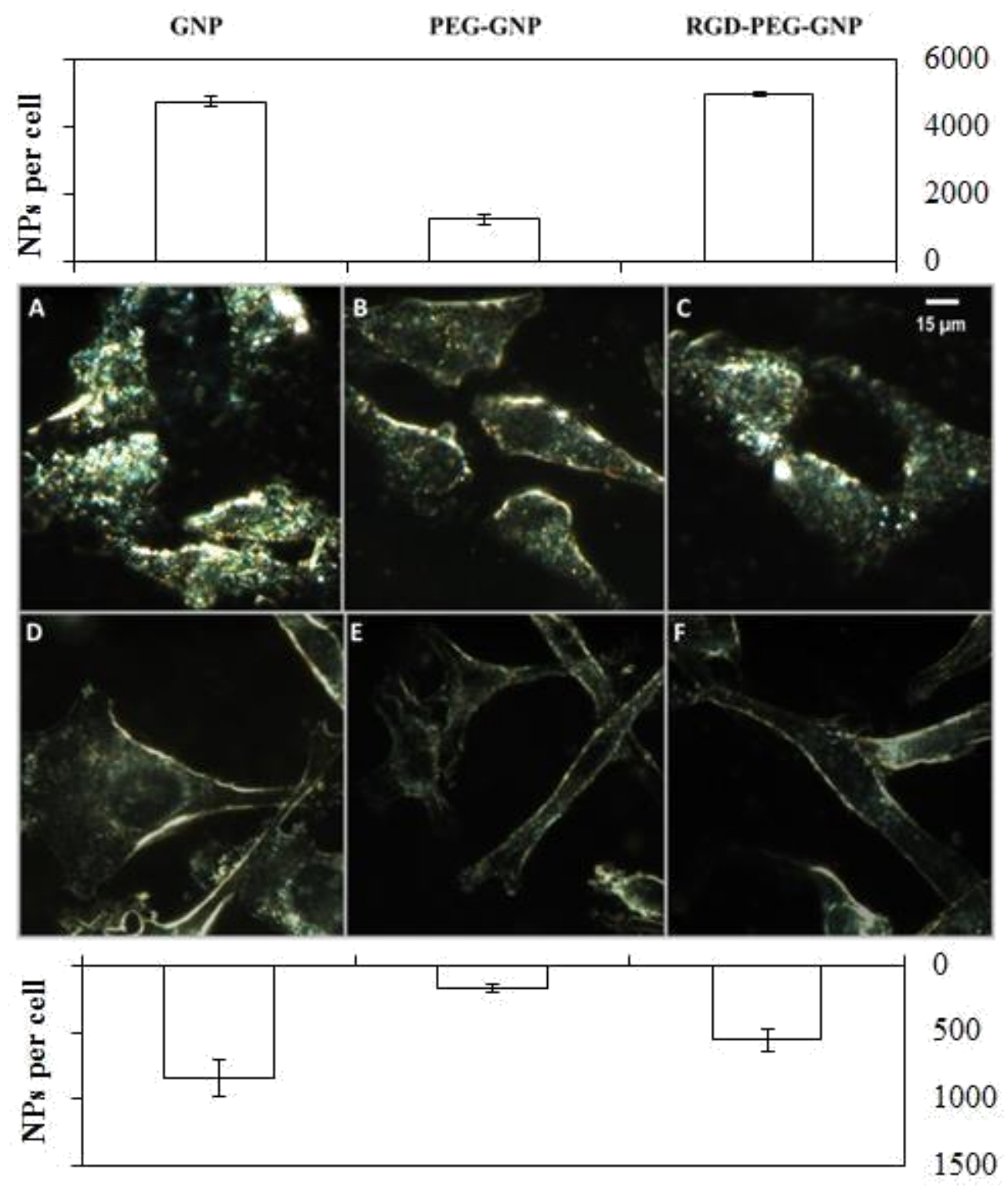

Figure 2.5 CytoViva darkfield images of $14 \mathrm{~nm}$ NPs in cancer cells and corresponding uptake. A) As-made GNP, B) PEG-GNP and C) RGD-PEG-GNP in HeLa cells and in MDA-MB-231 cells (D, E and F, respectively). 


\subsection{Contribution of authors to manuscript}

Dr. B. D. Chithrani was the primary investigator, conceived and designed the study, and reviewed and edited the manuscript. The first author performed and helped to conceive the study, collected and interpreted results, and wrote the paper.

\section{$\underline{2.12 \text { Permission for copyrighted material }}$}

Dear Prof. Chithrani:

American Scientific Publishers grants permission to reuse the following whole article or parts of it in the forthcoming MSc thesis to be submitted to the Ryerson University by Miss Charmainne Cruje.

Integration of Peptides for Enhanced Uptake of PEGylated Gold Nanoparticles Authors: C. Cruje and B. D. Chithrani

Best regards, H. S. Nalwa, PhD

Publisher

Dr. Hari Singh Nalwa | Editor-in-Chief: Journal of Nanoscience and Nanotechnology | Web: $\underline{\text { www.aspbs.com/jnn }}$ Editor: Encyclopedia of Nanoscience and Nanotechnology (25-Volume set) | Web: www.aspbs.com/enn American Scientific Publishers | 26650 The Old Road, Suite 208, Valencia, California 91381-0751, USA Phone: (661) 799-7200 |Fax: (661) 799-7230 | Email: nalwa@aspbs.com | Web: $\underline{w w w . a s p b s . c o m ~}$ 


\section{CHAPTER 3}

\section{SUMMARY AND FUTURE WORK}

This study found that the increase in cancer cell entry of surface-modified NPs is affected by core size since PEG grafting density changes with this property. Integrating targeting ligands of a single type on NP surface improved cancer cell entry of PEG-coated NPs. The targeting ligand used in this study showed dependence on cell line, which requires further study. A preliminary study on NP application in radiation therapy was done, which may be studied further. Other cancer therapy options like chemotherapy may also be studied. Finally, targeting may be taken a step further so that not only the cytoplasm is targeted, but also other organelles. This section suggests potential future studies that result from this study.

\subsection{Uptake dependence on varying peptide to PEG ratios}

A preliminary study was done on varying the amount of peptides added to 14 nm GNPs. Increasing peptide to PEG ratios from 20:80 to 50:50 significantly increases uptake of $14 \mathrm{~nm}$ PEG-GNPs in HeLa and MDA-MB-231 cells from 25\% and $7 \%$ to $78 \%$ and $46 \%$ of respective as-made GNPs (Figure 3.1). The integrin receptor affinity of RGD explains the more significant increase in HeLa cell uptake. 
Therefore, the same peptide to PEG ratio compensates for the minimized serum protein binding of GNPs due to PEG. These preliminary results show the need for investigating the effect of varying peptide to PEG ratios on cancer cell entry of PEGylated GNPs.

\section{$\underline{3.2 \mathrm{GNPs} \text { as radiosensitizers }}$}

\subsubsection{Radiation and GNP treatment}

A preliminary study was done using HeLa cells incubated with medium-sized (50 nm) GNPs followed by a single fraction treatment with a megavoltage photon beam (6 MeV). In addition, confluent dishes that were not incubated with NPs were prepared for use as control and for irradiation immediately after the addition of GNPs. An Elekta Synergy linear accelerator (Elekta Oncology Systems, Stockholm, Sweden) was used as a $6 \mathrm{MeV}$ photon source (Figure 3.2). Plastic bolus that was 20 mm thick, like the culture dish used, was cut out so that dishes were surrounded by water equivalent material in lieu of air. $100 \mathrm{~mm}$ of solid water was placed under the dish for backscatter while $80 \mathrm{~mm}$ was placed above it so that the monolayer was set up to a source-to-axis distance of $1000 \mathrm{~mm}$. A field size of $400 \mathrm{~mm}$ x $400 \mathrm{~mm}$ was used so that four dishes were irradiated with $2 \mathrm{~Gy}$ at a dose rate of $400 \mathrm{MU} / \mathrm{min}$ simultaneously. The survival fraction of irradiated samples were compared to nonirradiated and no GNP samples. 


\subsubsection{Survival fractions of irradiated cells}

A clonogenic assay was performed for all treatment conditions. 60-mm dishes were seeded with 100 cells from the control dish or 500 cells from the irradiated cultures. Three dishes were prepared per sample type. After two weeks of seeding, the number of colonies per dish were counted and compared to that of the control (Table 3.1 and Figure 3.3). For all samples irradiated with $6 \mathrm{MeV}$, all NP incubations were found to radiosensitize when compared to samples irradiated with no NPs. However, those incubated with GNPs and RGD-PEG-GNPs had lower survival rates compared to the use of PEG-GNPs. Hence, we were able to demonstrate that PEG-RGD combination facilitated higher radiosensitization. These preliminary results show the promise of using such surface modified GNPs for irradiation studies in vivo.

\section{$\underline{3.3 \text { Application in chemotherapy }}$}

Like the dependence of radiation dose-enhancing GNPs on cancer entry, its ability to deliver chemotherapeutic drugs also depends on intracellular localization. ${ }^{1,2}$ It has been found that 6-mercaptopurine-9-beta-d-ribofuranoside delivered by gold nanoparticles was more effective in treating K-562 leukemia cells compared to its

free form due to the intracellular transport GNPs offer. ${ }^{1}$ Methotrexate was also found more successful in treating HeLa and MCF-7 cells when delivered by iron oxide NPs. $^{2}$ In this regard, a similar experiment as performed in this manuscript may be done since therapeutic effect was found to improve when drugs are delivered by NPs 
(Figure 3.4). Chemotherapeutic drugs may be loaded onto PEG-GNP or RGD-PEGGNPs so that cancer cell treatment by NP-delivered drugs may be evaluated.

\subsection{Enhanced uptake using other membrane receptors}

The HeLa cell line used in this study displayed enhanced cancer cell uptake of NPs modified with both the targeting ligand and PEG for all NP sizes. On the other hand, the MDA-MB-231 cell line used only showed enhancement for small NPs and to a less extent compared to HeLa. Hence, another peptide sequence must be used in targeting PEG-GNPs in other cell lines (Table 3.2). For example, a study that used magnetic iron oxide NPs targeted urokinase plasminogen activator receptors. ${ }^{3}$ In this study, orthotopic human pancreatic cancer xenografts grown in nude mice were targeted using iron NPs. It was found effective in delivering the chemotherapeutic drug gemcitabine. It was also found effective in enhancing magnetic resonance imaging signals. To target GNPs into MDA-MB-231 cells, membrane receptor overexpression must be considered. For example, this cell line overexpresses the membrane glycoprotein PC-1. ${ }^{4}$ On a similar note, another breast cancer line, the MCF-7 cell line, was found to overexpress a type of the estrogen receptor on its cell

membrane. ${ }^{5}$ This may be taken advantage of in enhancing the uptake of PEG-GNPs. Upon confirming enhanced uptake, an experiment observing its therapeutic application may then be performed. 


\subsection{Organelle-targeting NPs}

Previous work has shown that radiation damage primarily caused in specific cellular compartments aside from the cytoplasm lead to improved therapeutic outcomes. It has been found that nuclear targeting of GNPs enhanced radiation

damage in HeLa cells. ${ }^{6}$ Mitochondrial damage has also been found to lead to cell death after radiation treatment. ${ }^{7}$ Here, surface modified GNPs were introduced to HeLa cells, and the authors attributed greater cell death of cancer cells due to mitochondrial damage. Surface modification done in this manuscript may be taken a step further by an additional modification with a molecule that will target or prefer localization in cellular compartments other than the cytoplasm (Figure 3.5). Therapeutic outcomes may improve when targeting PEG-GNPs to organelles such as the mitochondria or nucleus. Such future studies will accelerate clinical trials of GNPs, bringing it closer to medical use.

\section{$\underline{3.6 \text { References }}$}

1 P. Podsiadlo, V. A. Sinani, J. H. Bahng, N. W. Kam, J. Lee, and N. A. Kotov, "Gold nanoparticles enhance the anti-leukemia action of a 6-mercaptopurine chemotherapeutic agent," Langmuir : the ACS journal of surfaces and colloids 24 (2), 568-574 (2008).

2 N. Kohler, C. Sun, J. Wang, and M. Zhang, "Methotrexate-modified superparamagnetic nanoparticles and their intracellular uptake into human cancer cells," Langmuir : the ACS journal of surfaces and colloids 21 (19), 8858-8864 (2005). 
3 G. Y. Lee, W. P. Qian, L. Wang, Y. A. Wang, C. A. Staley, M. Satpathy, S. Nie, H. Mao, and L. Yang, "Theranostic nanoparticles with controlled release of gemcitabine for targeted therapy and MRI of pancreatic cancer," ACS nano 7 (3), 2078-2089 (2013).

4 A. Belfiore, A. Costantino, F. Frasca, G. Pandini, R. Mineo, P. Vigneri, B. Maddux, I. D. Goldfine, and R. Vigneri, "Overexpression of membrane glycoprotein PC-1 in MDA-MB231 breast cancer cells is associated with inhibition of insulin receptor tyrosine kinase activity," Molecular endocrinology 10 (11), 1318-1326 (1996).

5 C. Lattrich, I. Juhasz-Boess, O. Ortmann, and O. Treeck, "Detection of an elevated HER2 expression in MCF-7 breast cancer cells overexpressing estrogen receptor beta1," Oncology reports 19 (3), 811-817 (2008).

6 C. Yang, J. Uertz, D. Yohan, and B. D. Chithrani, "Peptide modified gold nanoparticles for improved cellular uptake, nuclear transport, and intracellular retention," Nanoscale 6 (20), 12026-12033 (2014).

7 Y. Pan, A. Leifert, D. Ruau, S. Neuss, J. Bornemann, G. Schmid, W. Brandau, U. Simon, and W. Jahnen-Dechent, "Gold nanoparticles of diameter $1.4 \mathrm{~nm}$ trigger necrosis by oxidative stress and mitochondrial damage," Small 5 (18), 2067-2076 (2009). 


\section{$\underline{3.7 \text { Tables and figures }}$}

Table 3.1 Survival fraction of irradiated and GNP treated HeLa cells

\begin{tabular}{|c|c|c|c|c|c|c|c|c|c|}
\hline \multicolumn{2}{|c|}{$\begin{array}{c}\text { Versus not irradiated, } \\
\text { no GNP sample }\end{array}$} & \multicolumn{2}{|c|}{ Trial 1} & \multicolumn{2}{|c|}{ Trial 2} & \multicolumn{2}{|c|}{ Trial 3} & \multicolumn{2}{|c|}{ Overall Survival Fraction } \\
\hline \multicolumn{2}{|c|}{ Treatment condition } & Average & Error & Average & Error & Average & Error & Average & Error \\
\hline \multirow{5}{*}{ Irradiated } & No GNP & 0.808 & 0.074 & 0.795 & 0.028 & 0.847 & 0.118 & 0.816 & 0.027 \\
\hline & GNP & 0.459 & 0.044 & 0.465 & 0.019 & 0.484 & 0.069 & 0.469 & 0.013 \\
\hline & PEG-GNP & 0.744 & 0.068 & 0.715 & 0.032 & 0.679 & 0.097 & 0.713 & 0.033 \\
\hline & RGD-PEG-GNP & 0.436 & 0.044 & 0.495 & 0.023 & 0.460 & 0.067 & 0.464 & 0.030 \\
\hline & $\begin{array}{l}\text { GNP, not } \\
\text { incubated }\end{array}$ & 0.734 & 0.067 & 0.739 & 0.031 & 0.749 & 0.104 & 0.741 & 0.008 \\
\hline \multirow{2}{*}{$\begin{array}{c}\text { Not } \\
\text { irradiated }\end{array}$} & No GNP & 1.000 & 0.129 & 1.000 & 0.046 & 1.000 & 0.196 & 1.000 & 0.000 \\
\hline & GNP & 1.114 & 0.106 & 0.968 & 0.118 & 1.113 & 0.183 & 1.065 & 0.084 \\
\hline
\end{tabular}


Table 3.2 Cell lines and proposed cell membrane receptor to be targeted.

\begin{tabular}{ccc}
\hline Cell Line & Cancer Type & Receptor Type \\
\hline \hline HeLa & Cervical & integrin \\
MDA-MB-231 & Breast & plasma cell membrane glycoprotein \\
MCF-7 & Breast & estrogen \\
MIA PaCa-2 & Pancreatic & urokinase plasminogen activator
\end{tabular}



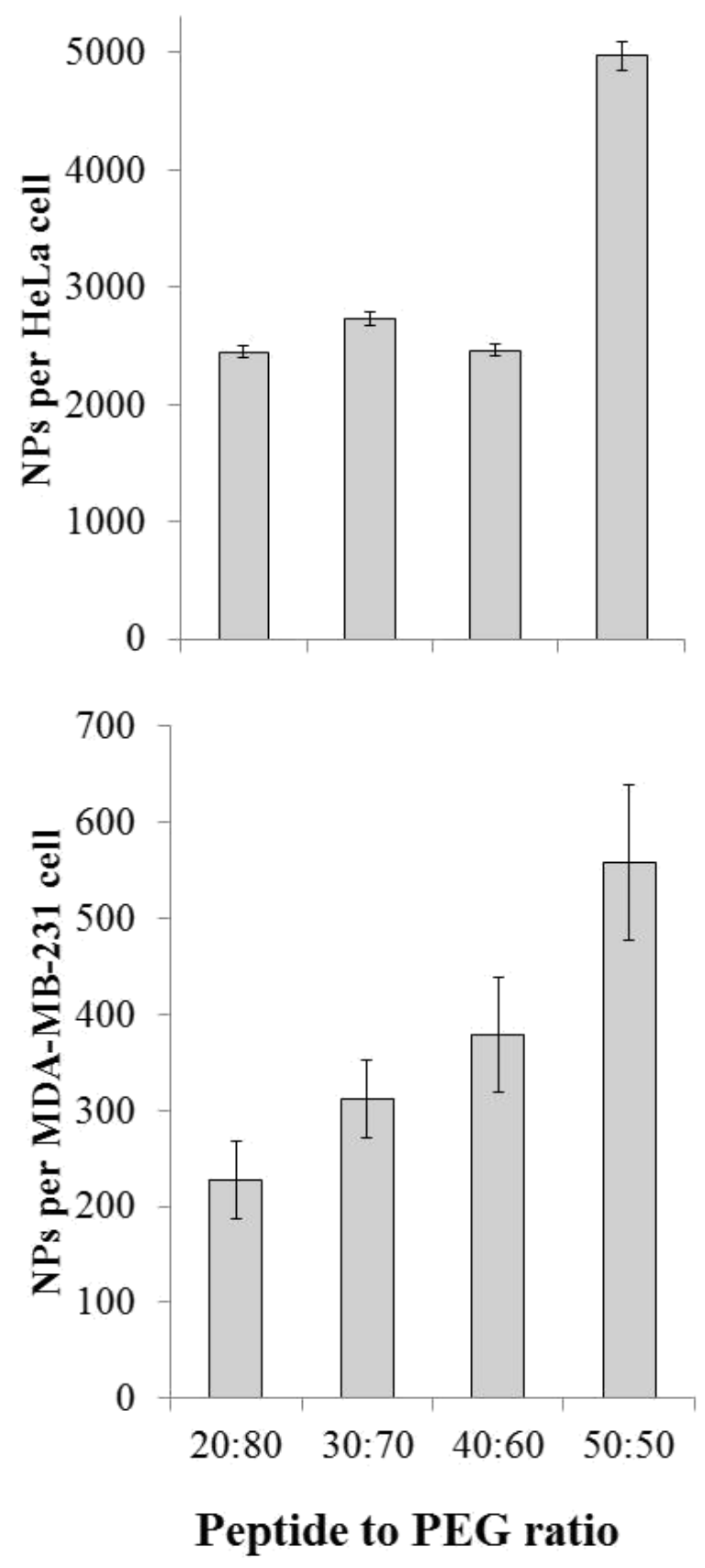

Figure 3.1 Peptide to PEG ratio dependence of uptake in A) HeLa cells and B) MDAMB-231 cells. 


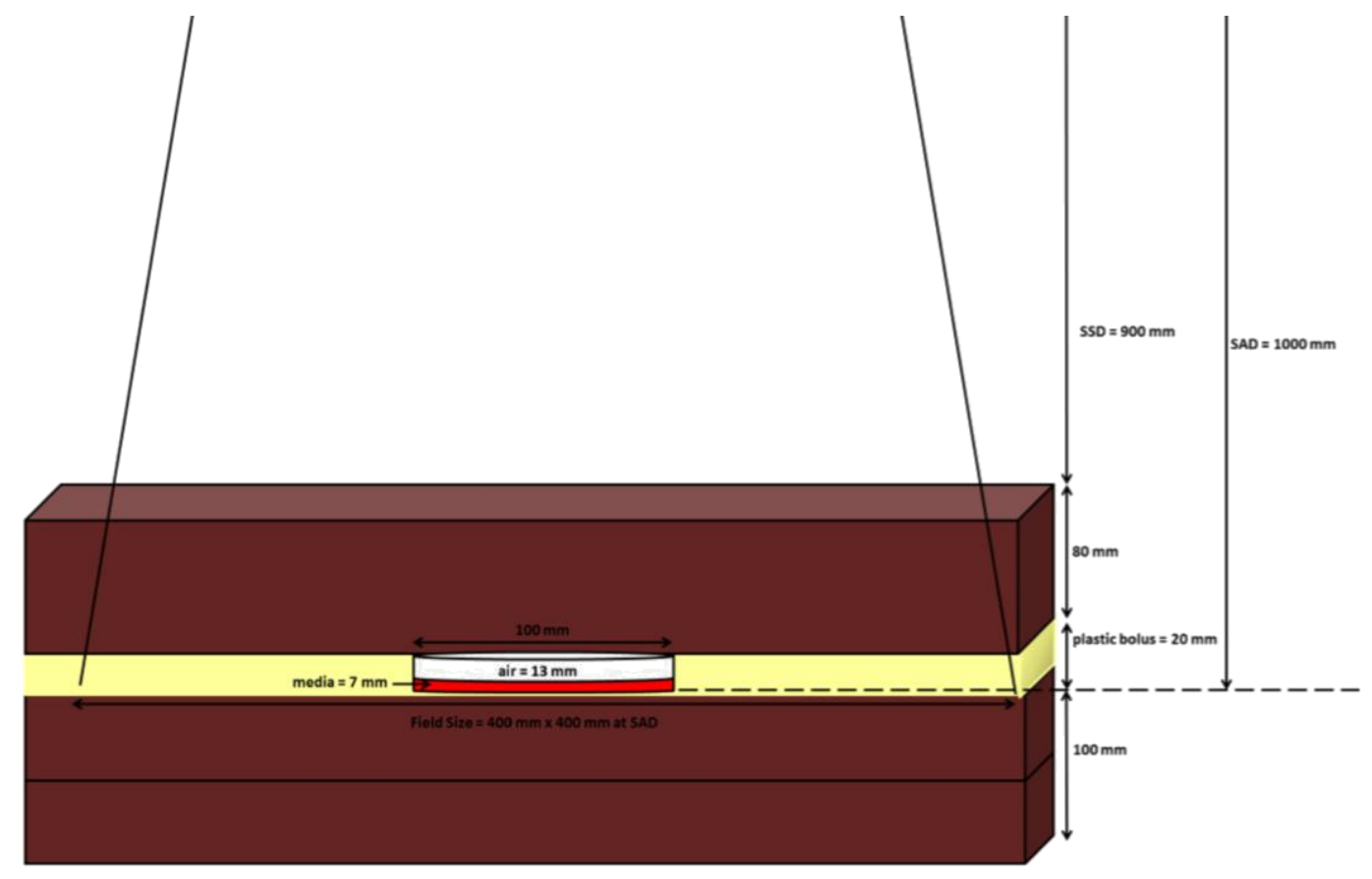

Figure 3.2 Irradiation experiment setup using $6 \mathrm{MeV}$ photons. To simulate a single dose radiation treatment, $100 \mathrm{~mm}$ dishes were placed between solid water and surrounded with plastic bolus. The monolayer was placed at a distance of $1000 \mathrm{~mm}$ from the source. A dose of $2 \mathrm{~Gy}$ was delivered as per standard single dose treatment. 


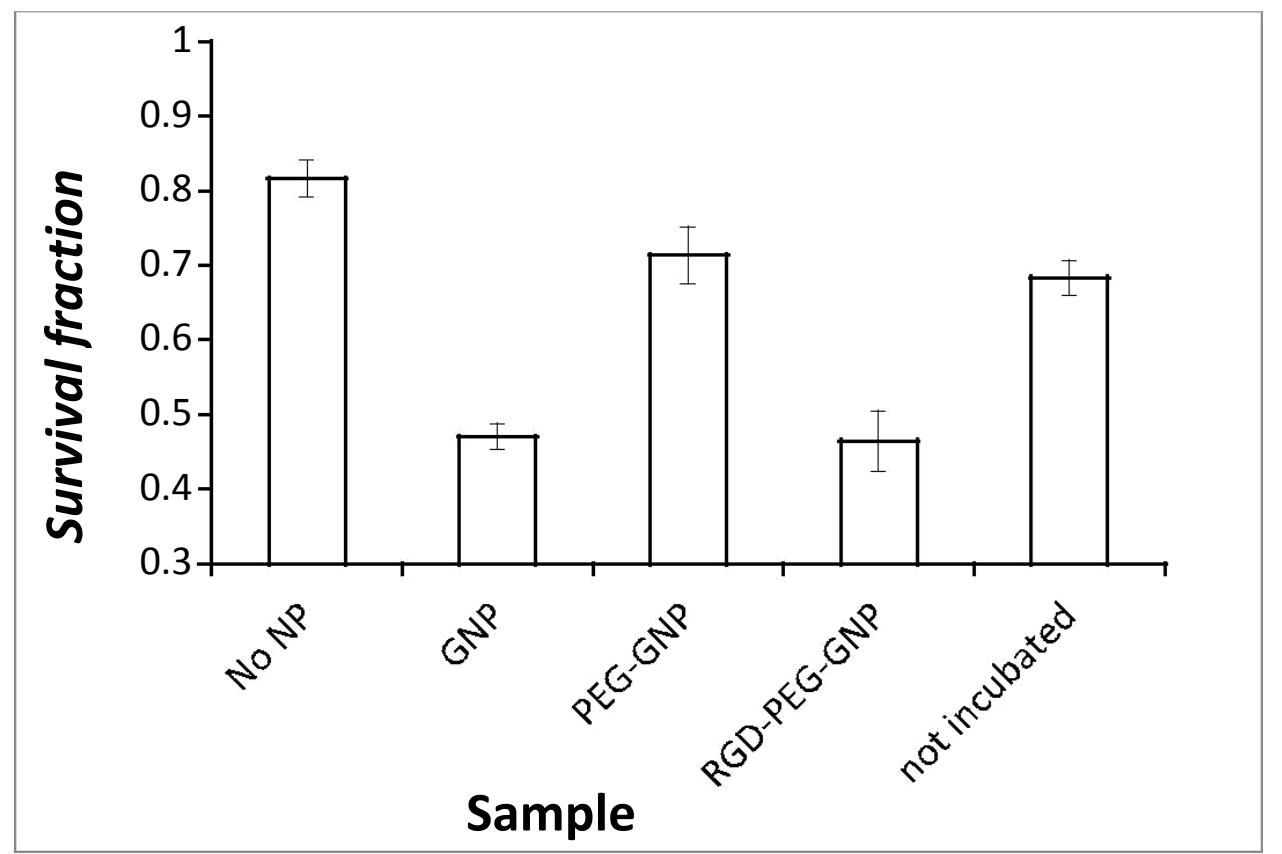

Figure 3.3 Survival fraction of HeLa cells treated with 2 Gy of $6 \mathrm{MeV}$ photons. 

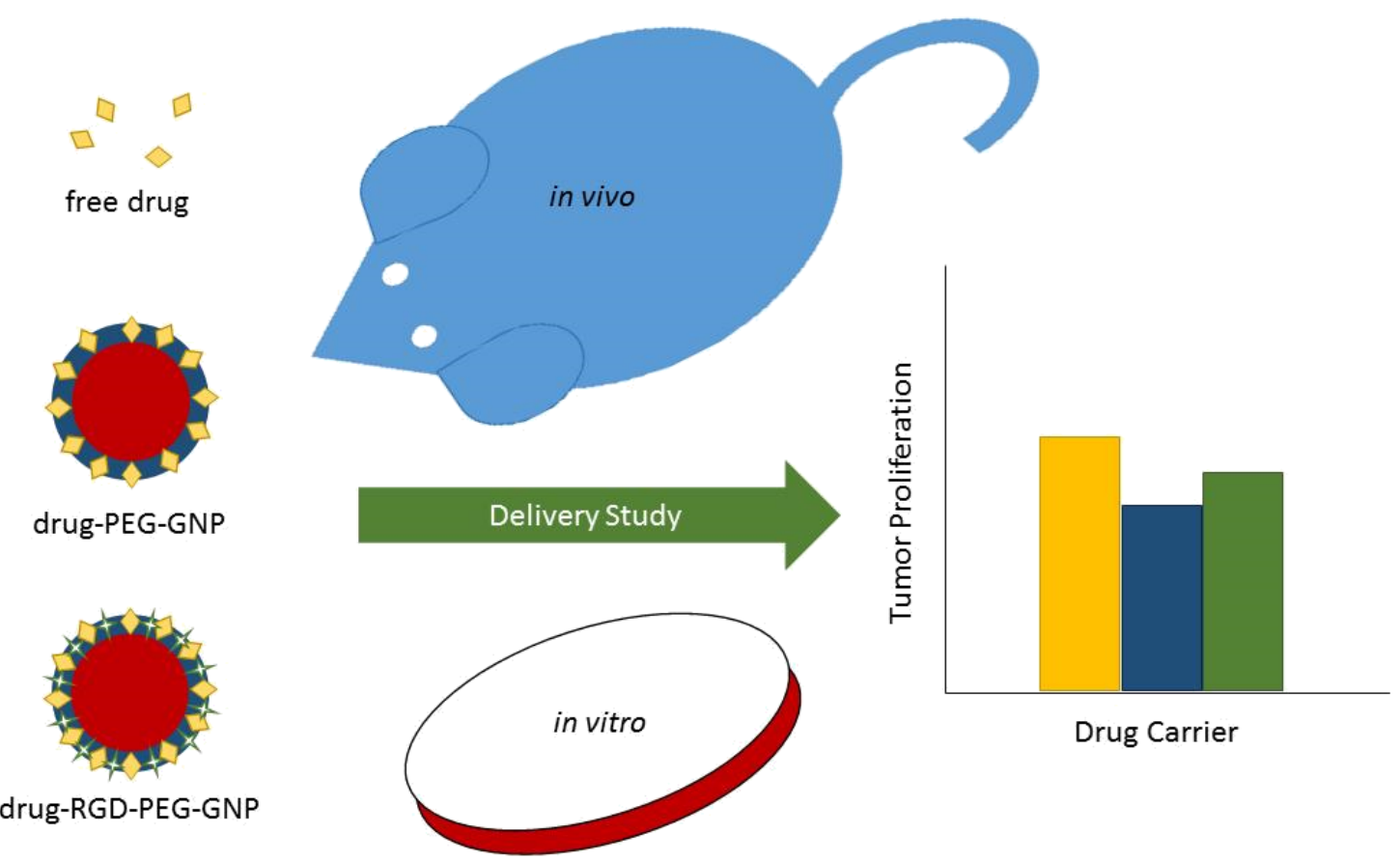

Figure 3.4 Proposed drug experiment using surface-modified GNPs as drug delivery vehicles. Further experiments may be done in vitro or in vivo to evaluate the efficiency of using tumor and cancer cell targeting GNPs by observing its ability to control tumor proliferation. 


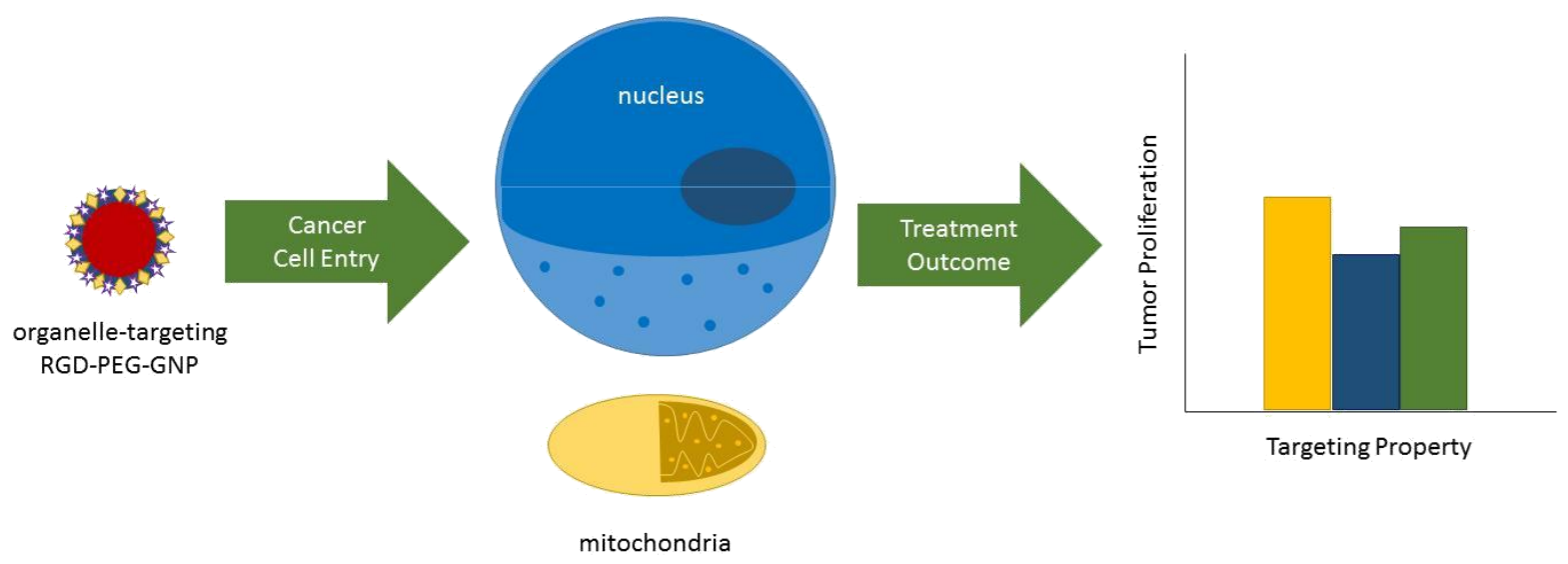

Figure 3.5 Proposed experiment with organelle-targeting RGD-PEG-GNPs. Previous studies have attributed higher cancer cell death due to organelle damage. Hence, GNP surface may be modified so that organelle damage is promoted. 